\title{
Nusselt Number and Friction Factor Correlations Development for Arc-Shape Apex Upstream Artificial Roughness in Solar Air Heater
}

\author{
Mukesh Kumar Sahu ( $\nabla$ mks.nitjsr@gmail.com ) \\ National Institute of Technology Jamshedpur \\ Manjeet Kharub \\ CVR College Of Engineering \\ Mahalingam Murugesan Matheswaran \\ Jansons Institute of Technology Department of Mechanical Engineering
}

\section{Research Article}

Keywords: Solar air heaters, Nusselt number Enhancement Ratio, Friction factor Enhancement Ratio, Thermo-hydraulic Improvement Parameter.

Posted Date: December 30th, 2021

DOI: https://doi.org/10.21203/rs.3.rs-1119494/v1

License: (c) (i) This work is licensed under a Creative Commons Attribution 4.0 International License. Read Full License 
1 Nusselt Number and Friction Factor Correlations Development for 2 Arc-Shape Apex Upstream Artificial Roughness in Solar Air Heater

3

\title{
Corresponding author:
}

Contact Email ID: manjeetkharub@gmail.com; mks.nitjsr@gmail.com

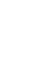

\author{
Mukesh Kumar Sahu ${ }^{\mathbf{a}, \mathbf{b}}$, Manjeet Kharub ${ }^{\mathbf{c}}$, Mahalingam Murugesan Matheswaran ${ }^{\mathrm{d}}$
}




\title{
Nusselt Number and Friction Factor Correlations Development for Arc-Shape Apex Upstream Artificial Roughness in Solar Air Heater
}

\author{
Mukesh Kumar Sahu ${ }^{\mathbf{a}, \mathbf{b}}$, Manjeet Kharub ${ }^{\mathbf{c}}$, Mahalingam Murugesan Matheswaran ${ }^{\mathrm{d}}$
}

${ }^{a}$ National Institute of Technology, Jamshedpur, Jharkhand, India

${ }^{\mathrm{b}}$ Cambridge Institute of Technology, Tatisilwai, Ranchi, Jharkhand, India

${ }^{\mathrm{c}}$ CVR College of Engineering Hyderabad

${ }^{\mathrm{d} J a n s o n s}$ Institute of Technology, Karumathampatti, Coimbatore, Tamil Nadu, India

\section{Corresponding author: \\ Contact Email ID: manjeetkharub@gmail.com; \\ mks.nitjsr@gmail.com}

\begin{abstract}
In the present work an outdoor experimental investigation for solar air heater with arc-shaped apexupstream flow by the use of circular cross section wires as roughness elements has been carried out. The roughness-element have been expressed in non-dimensionalizing geometric parameters as relative roughness-pitch $(\mathrm{P} / \mathrm{e})$, relative roughness-height (e/D) and flow attack-angle $(\alpha / 60)$, and the range of these parameters varies from 8 to $15,0.0454$, and 0.75 to 1.25 , respectively.
\end{abstract}

For evaluation of performance of the roughened $\mathrm{SAH}$, a novel parameter has been proposed and introduced in the present investigation which is Thermo-Hydraulic Improvement Parameter (THIP). With the use of present roughness geometry, considerably Nusselt number enhancement ratio (NNER) and friction factor enhancement ratio (FFER) have been observed. The maximum NNER and FFER values obtained experimentally is about 2.83 and 1.79 times, respectively. While, the maximum THIP has been obtained $157.49 \%$ higher than the smooth SAH. Using the experimental results correlations for the output parameters (Nusselt number and friction factor) as a function of input parameters (flow and roughness) have been developed.

Keywords: Solar air heaters; Nusselt number Enhancement Ratio; Friction factor Enhancement Ratio; Thermo-hydraulic Improvement Parameter. 

$A_{c} \quad$ Surface area of absorber plate $\left(\mathrm{m}^{2}\right)$
$\mathrm{p}_{\mathrm{a}} \quad$ Atmospheric pressure $\left(\mathrm{N} / \mathrm{m}^{2}\right)$
$A_{o} \quad$ Cross sectional area of orifice $\left(\mathrm{m}^{2}\right)$
$\mathrm{Qu} \quad$ Useful heat gain (W)
$\mathrm{C}_{\mathrm{pa}} \quad$ Specific heat of air $(\mathrm{J} / \mathrm{kg} \mathrm{K})$
$\mathrm{V} \quad$ Velocity of air $(\mathrm{m} / \mathrm{s})$
$C_{d}$ Coefficient of discharge for orifice meter
$\mathrm{T}_{\text {sun }} \quad$ Sun temperature $(\mathrm{K})$
e Height of roughness (m)
$\mathrm{T}_{\mathrm{g}} \quad$ Cover glass Temperature $\left({ }^{\circ} \mathrm{C}\right)$
G Mass velocity of air $(\mathrm{m} / \mathrm{s})$
$\mathrm{T}_{\mathrm{fo}} \quad$ Outlet air temperature $\left({ }^{\circ} \mathrm{C}\right)$
h Heat transfer coefficient $\left(\mathrm{W} / \mathrm{m}^{2} \mathrm{~K}\right)$
$\mathrm{T}_{\mathrm{s}} \quad$ Sky temperature $(\mathrm{K})$
$h_{w}$ Convective heat transfer coefficient due to $\mathrm{h}_{\mathrm{w}}$ wind $\left(\mathrm{W} / \mathrm{m}^{2} \mathrm{~K}\right)$
H SAH Duct depth (m)
$\mathrm{T}_{\mathrm{fi}} \quad$ Inlet Air Temperature $\left({ }^{\circ} \mathrm{C}\right)$
I Intensity of global solar radiation (Insolation) $\left(\mathrm{W} / \mathrm{m}^{2)}\right.$
$\mathrm{T}_{\mathrm{a}} \quad$ Ambient temperature $\left({ }^{\circ} \mathrm{C}\right)$
$\mathrm{K}_{\mathrm{a}} \quad$ Thermal conductivity of air (W/mK)
$\mathrm{T}_{\mathrm{pm}}$
Mean absorber plate temperature $\left({ }^{\circ} \mathrm{C}\right)$
$\mathrm{T}_{\mathrm{fm}} \quad$ Mean air temperature $\left({ }^{\circ} \mathrm{C}\right)$
$\mathrm{K}_{\mathrm{g}}$ Thermal conductivity of glass cover $(\mathrm{W} / \mathrm{mK})$
$\mathrm{T}_{\mathrm{bm}}$
Mean temperature of bottom plate $\left({ }^{\circ} \mathrm{C}\right)$
$\mathrm{K}_{\mathrm{i}} \quad$ Thermal conductivity of glass wool insulation (W/mK)
e/D Relative roughness height
L Length of solar air heater duct (m)
f Friction factor
$\mathrm{L}_{1} \quad \begin{aligned} & \text { Spacing } \\ & \text { plate }(\mathrm{m})\end{aligned}$
Pr Prandtl number
$\mathrm{L}_{\mathrm{g}} \quad$ Thickness of glass cover $(\mathrm{m})$
P/e Relative roughness pitch
$\dot{\mathrm{m}}$ Mass flow rate of air $(\mathrm{kg} / \mathrm{s})$
Re Reynolds number
$\Delta \mathrm{P}$ Pressure drop across the collector duct $\left(\mathrm{N} / \mathrm{m}^{2}\right)$
$\mathrm{Nu}$
Nusselt number

\section{Greek Symbols}

68

$\mu \quad$ Absolute viscosity of air $\left(\mathrm{N} \mathrm{s} / \mathrm{m}^{2}\right)$

$\eta_{\text {MTHIP }}$

Modified Thermo-hydraulic

$\rho \quad$ Air density $\left(\mathrm{kg} / \mathrm{m}^{3}\right)$

Improvement Parameter

$\rho_{\mathrm{m}} \quad$ Manometric fluid density $\left(\mathrm{kg} / \mathrm{m}^{3}\right)$

\section{Suffix}

T Temperature 


\begin{tabular}{|c|c|c|c|}
\hline$\alpha$ & Angle of attack $\left({ }^{\circ}\right)$ & GI & Galvanized Iron \\
\hline$\sigma$ & $\begin{array}{l}\text { Stefan-Boltzmann's constant } \\
\left(\mathrm{W} / \mathrm{m}^{2} \mathrm{~K}^{4}\right)\end{array}$ & $\mathrm{SAH}$ & Solar Air Heater \\
\hline$\delta_{i}$ & Thickness of insulation (m) & $\mathrm{R}$ & Roughened \\
\hline$\beta$ & Tilt angle of collector surface $\left(^{\circ}\right)$ & $S$ & Smooth \\
\hline$v$ & Air kinematic viscosity $\left(\mathrm{m}^{2} / \mathrm{s}\right)$ & $\mathrm{r}$ & Roughened \\
\hline$\alpha / 90$ & Relative angle of attack & $\mathrm{s}$ & Smooth \\
\hline$\varepsilon_{\mathrm{p}}$ & Emissivity of absorber plate & & \\
\hline$\eta_{t h}$ & Thermal efficiency & & \\
\hline$\beta_{R}$ & $\begin{array}{l}\text { Ratio of orifice diameter }\left(D_{2}\right) \text { to pipe } \\
\text { internal diameter }\left(D_{1}\right) \text {. }\end{array}$ & & \\
\hline
\end{tabular}

\section{Introduction}

Solar energy is the emergence source of energy that's abundant in nature and cheaper to work with and acquire monumental utilizations, moreover directly or by turning it into useful convenient forms of energy (Duffie and Beckman 1974). It can be utilized by conversion into useful heat or thermal in many manners with using solar energy conversion systems (Duffie and Beckman 1974; Garg and Prakash 2000). Flat plate solar collectors are in use globally for solar energy conversion systems and processes due to the simple construction framework, simple functionality and initail low price for the installation.

Various researchers have noticed that the energy conversion system's performance is low because of inadequate heat transfer/exchange between the absorber plate and working fluid and hence higher heat loss to the ambient (Sukhatme and Nayak 2011).

Invetigators have integrated several heat transfer enhancement methods like artificial roughness, packed bed materials, extended surfaces and baffles, V-groove, wavy and corrugated profile plates, winglets and turbulators on the absorber plate to enhance the flat plate solar air heater performance (Kabeel et al. 2017; Sahu et al. 2019; Sahu et al. 2016).

Among the above stated heat transfer enhancement techniques, artificial roughness improves the convective heat transfer between the air and absorber plate in a better way and hence we obtained 
improvement in the thermal performance of the SAH. It breaks the laminar sub-layer formulation and effectively reattaches the airstreams in the boundary layer for better heat transfer. These artificial roughness also increase in the friction factor and thus requires more pumping power compare with conventional SAH.

Sahu and Prasad (2016) have reported a review article on the use of various types of artificial roughness elements, its geometries, and working mechanics for rectangular SAH ducts.

Artificial roughness of different roughness elements is being arranged systematically in a repeated form on the absorber plate called roughness geometries. The arrangement of repeated roughness elements, guides the secondary flow in the stream-wise direction and helps to obtain the uniform augmentation of heat transfer all over the absorber plate.

Due to use of roughness, the turbulence gets produced in the core (main) flow and also there is development of secondary swirls /vortices just behind of these roughness elements (Sahu and Prasad 2016) . These phenomena resulted in better augmentation of convective heat transfer from absorber plate to the fluid. Many investigators used the circular cross-section small wires for fabricating the various geometry designs of the artificial roughness. These roughness geometries are named transverse, continues inclined, continues V-shape, arc shape and further it is modified into broken, multiple broken and discrete designs, which have been reported by the investigators.

Aharwal et al. (2008) modified the inclined ribs with providing a sinle gap and by this they obtained enhancement in heat transfer and friction factor values of 2.59 and 2.87 , respectively.

The performance of W-up and W-down ribs are compared by Lanjewar et al. (2011). Maximum thermohydraulic performance has been attained for $\mathrm{W}$-down ribs at an angle of attack of $60^{\circ}$. Momin et al. (2002) and Lanjewar et al. (2011) have developed the correlations for Nusselt number and friction factor for the $\mathrm{V}$ and $\mathrm{W}$ shaped roughness configurations of the SAHs, respectively. Singh et al. (2014) experimentally investigated effects of multiple arc ribs on heat transfer and friction factor and reported developed correlations for $(\mathrm{Nu})$ and (fr).

Multiple-arc with symmetrical gaps geometry has been investigated by Kumar et al. (2021). They found 5.57 times enhancement in Nusselt number and 4.46 times enhancement in friction factor. Kumar et al. (2019) optimized the thermal performance by response surface methodology (RSM) for discrete multiple arc-shaped rib roughness $\mathrm{SAH}$. 
Kumar et al. (2020) modified the multiple arc shape ribs into multiple arc with gaps ribs. Pandey et al. (2016) introduced gaps in multiple arc shape and experimentally investigated the effects of broken arc roughness designs on heat transfer and friction factor.

Gill et al. (2017) proposed the novel staggered-rib attached with the broken arc roughness which improves the Nusselt number and friction factor by 2.63 and 2.44 times compared to smooth duct SAH. All the researchers have attached the ribs with a circular cross-section as the artificial roughness over the absorber plate and developed the Nusselt number and frictional factor correlations as a function of design and operating conditions.

Kumar et al. (2021) have compared the exergetic efficiency of triangular SAH with semicircular and square roughness geometries and reported that semicircular ribbed triangular SAH is $26 \%$ more than square roughness.

Saini and Saini (2008) carried out the experimental analysis and developed the correlations for arcshape with apex downstream flow SAH. Saini and Saini (2008) have analyzed the influence of relative roughness height $(\mathrm{e} / \mathrm{D})$ and relative angle of arc $(\alpha / 90)$ while the relative roughness pitch (P/e) was constant for the arc shape with apex downstream flow SAH.

Sahu et al. (Sahu and Prasad 2016; Sahu and Prasad 2016; Sahu and Prasad 2017; Sahu and Prasad 2017) further optimized the arc-shaped down stream roughened SAH based on the effective, exergy and entropy generation based analysis respectively and obtained the design plots as a function of the temperature rise parameter.

Further (Ghritlahre et al. 2020; Sahu et al. 2021) have reported their experimental work to explore the consequence of different orientations, i.e., apex-downstream and apex-upstream flow of arc shape roughness on heat transfer, friction factor, thermal efficiency and pumping/mechanical work of SAH duct and found that apex-upstream flow has better performance over to apex-downstream.

From the above literature survey it is found that no authors have developed and reported the correlations for Nusselt number and friction factor having apex upstream- arc-shape roughened absorber plate on the rectangular SAH.

The aim of present work is to develop the correlations for Nusselt number and friction factor by using the experimental data. 

presented for comparing the enhancement by using the roughness on absorber with respect to smooth plate SAH for same operating parameters.

\section{Experimental program}

The experimental test rig has been designed and made up of according to the guidelines of ASHRAE standards (1977). The experimental setup consists of a wooden duct in a rectangular crosssection, and it comprises entrance, test and exit sections as shown in Fig.1. An induced draft blower with a capacity of $3.5 \mathrm{~kW}$ is used to suck the air from the ambient.

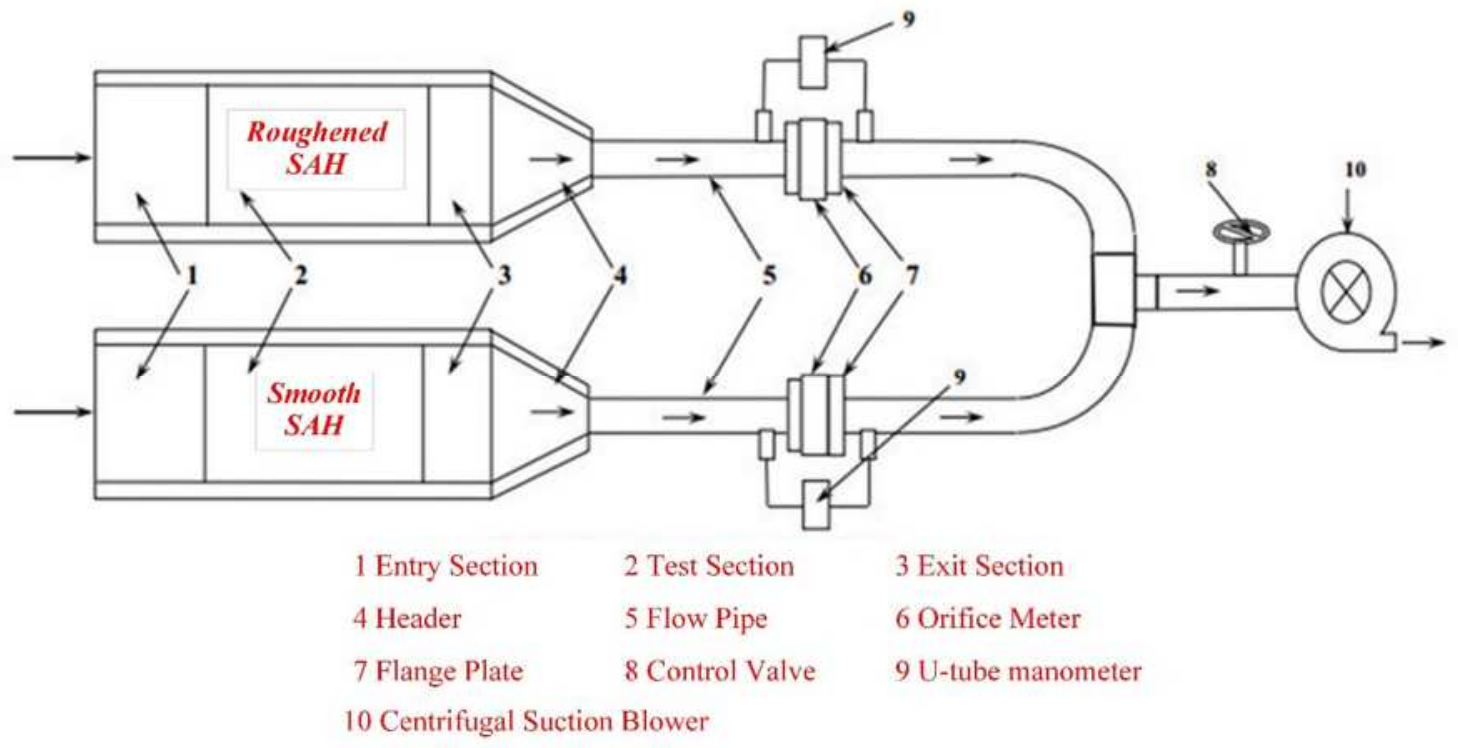

155

156

157

158

159

160

161

162

163

164

165

166

Fig. 1 Schematic view of the Experimental Set-up.

The duct is designed with a span of $2150 \mathrm{~mm}$, the width of $330 \mathrm{~mm}$ and height of $30 \mathrm{~mm}$. In test section of $1200 \mathrm{~mm}$ is covered with transparent glass to permit solar radiation as a test section among this total length. As per the guidelines, the ASHRAE duct should have minimum entry and exit sections; therefore, the duct has $650 \mathrm{~mm}$ entry and $300 \mathrm{~mm}$ exit length, respectively, with an aspect ratio $(\mathrm{W} / \mathrm{H})$ of 11 . The base and sides of the duct have been made up of $19 \mathrm{~mm}$ thick plywood. Both ducts contain a $4 \mathrm{~mm}$ glass sheet on top and a $3 \mathrm{~mm}$ G.I. sheet as a back plate. Glass wool with the thickness of $50 \mathrm{~mm}$ has been given between the bottom plate and plywood to minimize the bottom heat loss to the ambient. The volumetric flow rate of air for both SAH ducts are controlled to desirable values with the help of the main control valve. 
A $1 \mathrm{~mm}$ thick G.I. sheets with $1200 \mathrm{~mm} \times 330 \mathrm{~mm}$ specifications was utilized in smooth and roughened SAH ducts. In addition, a Circular wire having a $2.5 \mathrm{~mm}$ diameter was used for the roughness element.

Fig. 2 shows the roughened absorber plate with arc-shaped roughness with Apex-up flow. 173 Table-1 shows the details of roughness geometry and operating parameters that have been 174 considered in the present experimentation.

Test data were recorded in outside conditions from February to May in clear sky and on bright days between 10.00 to 14.00 hours at an interval of half-hour.

For each test conducted, the information such as absorber plate temperatures, outlet and inlet air temperatures, pressure drop across the duct were taken once the system obtained a steady state.

179 The steady-state was considered that when the temperature remains the same at least $30 \mathrm{~min}$.

Table. -1. Range of roughness and operating parameters

\begin{tabular}{|c|l|c|c|}
\hline Parameters & \multicolumn{1}{|c|}{ Name of Parameter } & Symbol & Values/ Range \\
\hline \multirow{3}{*}{ Roughness } & Relative roughness pitch & $P / e$ & $8-15$ (3 Values) \\
\cline { 2 - 4 } & Relative roughness height & $e / D$ & 0.0454 \\
\cline { 2 - 4 } & Angle of attack & $\alpha$ & $45^{\circ}-75^{\circ}$ (3 Values) \\
\hline Operating & Reynolds number & $R e$ & $2983-13955$ (6 Values) \\
\hline
\end{tabular}



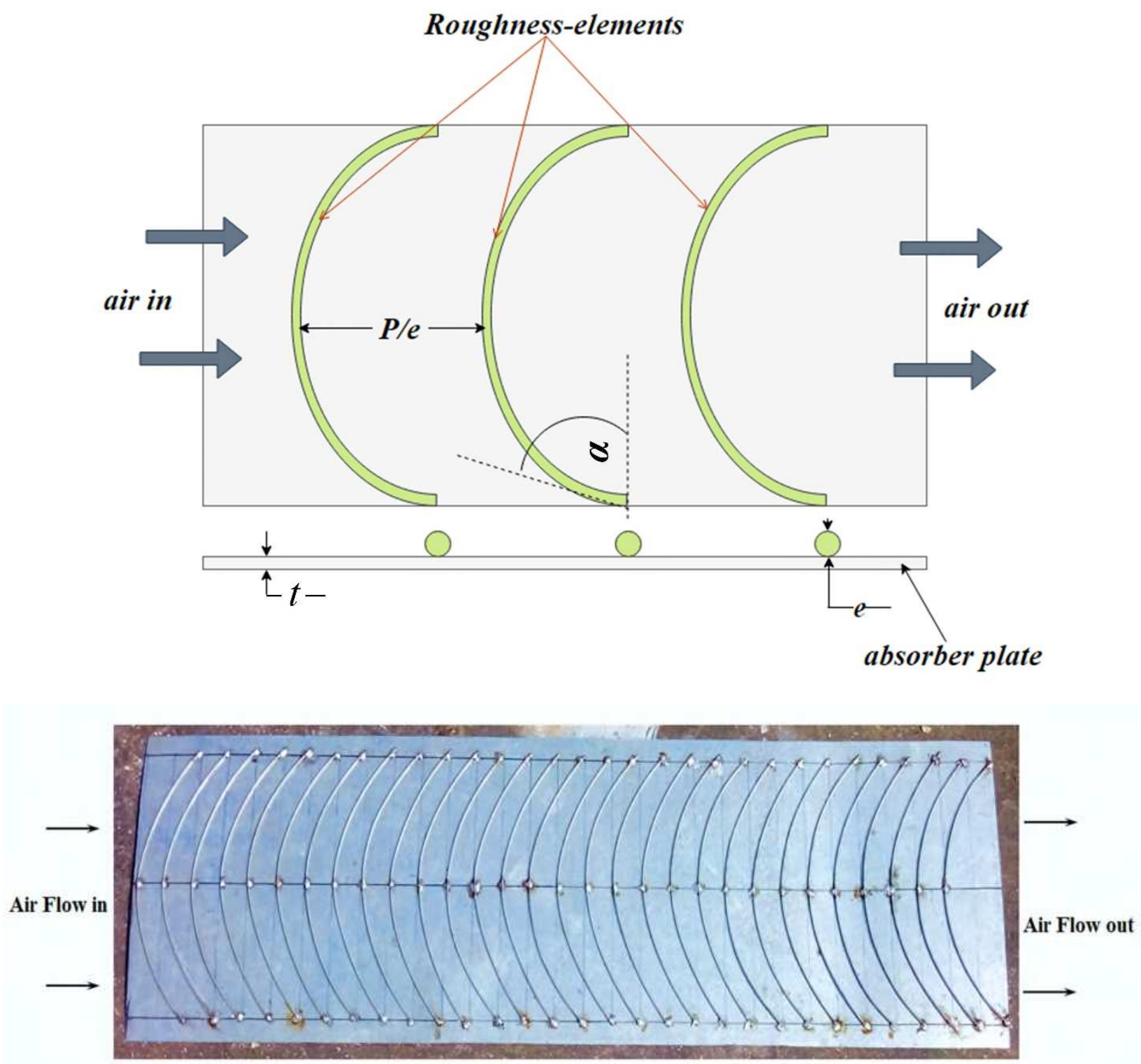

Fig. 2. Schematic and Photograph of arc shape roughness on absorber plate with Apex-up stream flow.

\section{Data reduction}

The air mass flow rate ' $\dot{m}$ ', was measured by a calibrated orifice meter which is calculated by 190 (Lanjewar et al. 2011; Pandey et al. 2016).

$$
n k=C_{d} A_{o} \sqrt{\frac{2 \rho_{a} \cdot(\Delta P)}{1-\beta_{R}{ }^{4}}}
$$


192 The pressure drops $\left(\Delta P_{o}\right)$ across the orifice meter has been calculated by using the Eq. (2) which is 193 given below (Lanjewar et al. 2011; Pandey et al. 2016).

$$
\Delta P_{o}=\rho g \Delta h\left(\frac{\rho_{m}}{\rho}-1\right)
$$

194 To assess the air temperature at the inlet and outlet of the test segment and the absorber plate, digital temperature indicators that provide output/results in ${ }^{\circ} \mathrm{C}$ with the precision of $0.1{ }^{\circ} \mathrm{C}$ have been utilized. Fig. 3 shows the places and locations of temperature indicators.

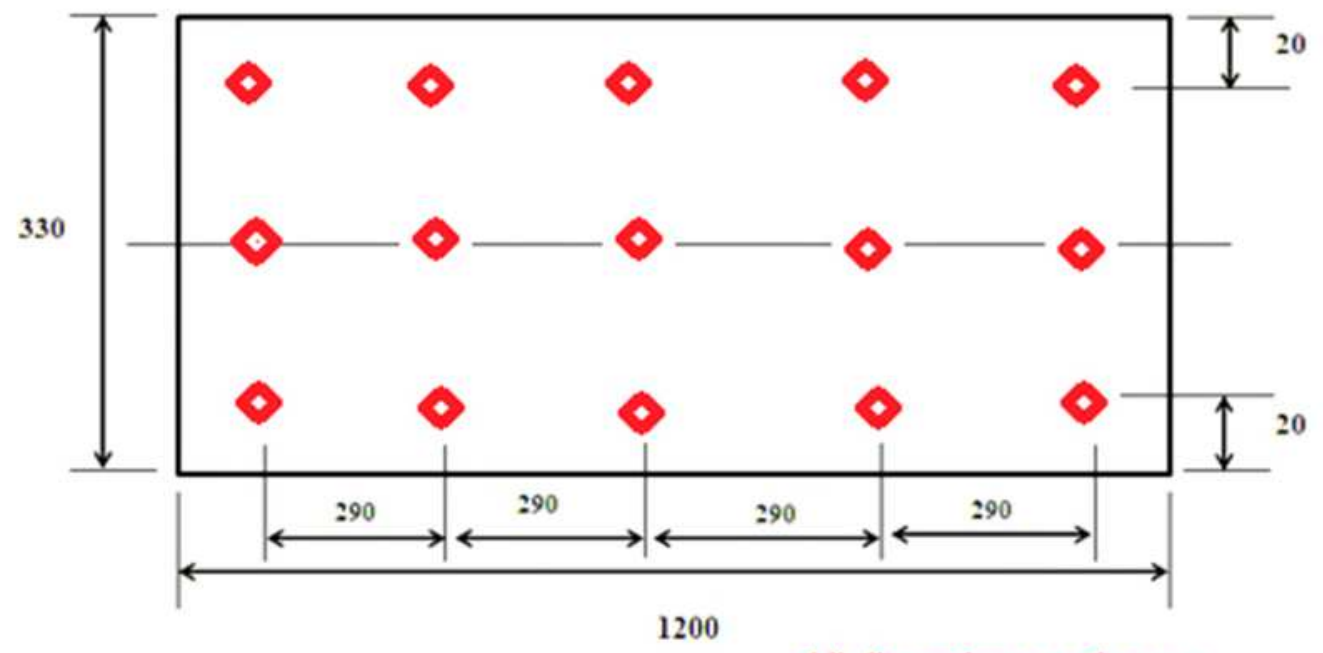

\section{All dimensions are in $m m$}

197

198

199

200

201

202

$T_{f m}=\frac{T_{f i}+T_{f o}}{2}$

203

Fig. 3. Digital temperature indicators positioning on Absorber Plate and at entry and exit sections of the duct.

Average temperatures values of air $\left(\mathrm{T}_{\mathrm{fm}}\right)$ and average temperatures values of absorber plate $\left(\mathrm{T}_{\mathrm{pm}}\right)$ are calculated by Eq. (3) and (4) respectively.

$$
T_{p m}=\frac{T_{1}+T_{2}+T_{3}+T_{4}+\ldots \ldots \ldots \ldots T_{15}}{15}
$$

The heat gained by the air passing through the SAH duct was calculated by using the Eq. (5) 


$$
Q_{u}=m \cdot C_{p a}\left(T_{f o}-T_{f i}\right)
$$

205 By applying the Newton's law of cooing the convective heat transfer coefficient between air and

206 absorber plate is evaluated by Eq. (6)

$$
h=\frac{Q_{u}}{A_{c}\left(T_{p m}-T_{f m}\right)}
$$

207 Using the Eq. (7) the Nusselt number is evaluated which is given by

$$
N u=\frac{h D_{h}}{K_{a}}
$$

208 Where

209

$$
D=\frac{2 . W . H}{(W+H)}
$$

210

211 Friction factor (f) for both the collectors test sections were calculated by using the Eq. (9) (Lanjewar 212 et al. 2011; Pandey et al. 2016; Kumar 2019).

$$
f=\frac{2 \cdot \rho \cdot\left(\Delta P_{D}\right) D}{4 L_{f} G^{2}}
$$

213

214 Where

215

$$
G=\left(\frac{n \&}{W . H}\right) \text { is mass velocity of air inside the duct. }
$$

216 The Reynolds number (Re) was evaluated by using the Eqn. (10)

$$
\operatorname{Re}=\frac{G D}{\mu}
$$

\section{Comparison of Performance Parameter}

218 Equations 11 to 15 and Table-2 detail the various performance parameters used for the 219 analysis and comparison of $\mathrm{SAH}$ 

221 given by different authors. 


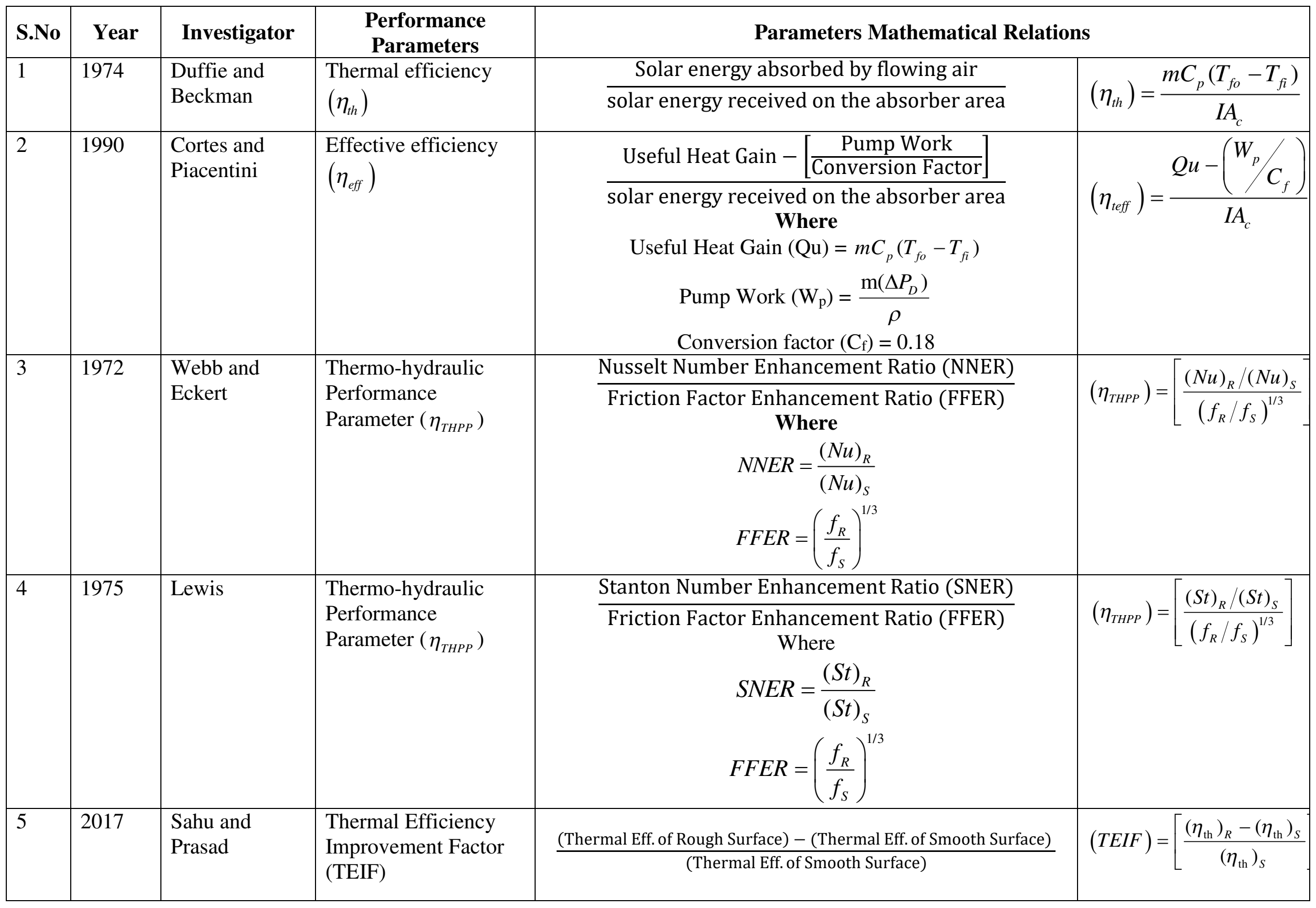




$\left.\begin{array}{|l|l|l|l|l|}\hline 6 & \text { Present Study } & \begin{array}{l}\text { Thermo-hydraulic } \\ \text { Improvement Factor } \\ \left(\varepsilon_{\text {THIF }}\right)\end{array} & \begin{array}{c}\text { Nusselt Number Improvement Factor (NNIF) } \\ \text { Friction Factor Improvement Factor (FFIF) } \\ \text { Where }\end{array} & \left(\varepsilon_{\text {THIF }}\right)=\left[\frac{(N N I F)}{(F F I F)}\right] \\ & N N I F=\left[\frac{(N u)_{R}-(N u)_{S}}{(N u)_{S}} \times 100\right] \\ & F F I F=\left[\frac{\left(f_{R}\right)-\left(f_{S}\right)}{\left(f_{S}\right)} \times 100\right]\end{array}\right]$


223 Artificial roughness in the SAH duct augments the heat transfer; at the same time, besides this, it is 224 also responsible for increases in the friction or pumping power as a penalty; hence, the roughness 225 geometry ought to be able to enhance the heat transfer with least raise in friction factor (Cortes and 226 Piacentini 1990). Therefore for comparison of augmentation in thermo-hydraulic performance 227 parameter (THPP), i.e., modified surface as compared to reference (smooth) surface, a parameter 228 has been investigated and reported by Webb and Eckert (1972).

229

$$
\eta_{T H P P}=\frac{\left(N u_{R} / N u_{S}\right)}{\left(f_{R} / f_{S}\right)^{1 / 3}}
$$

230 The Eq. 11 (a) given by Webb and Eckert (1972) for evaluating thermo-hydraulic performance 231 parameter (THPP) and it can be stated as:

232

$$
T H P P=\frac{\text { Nusselt Number Enhancement Ratio (NNER) }}{\text { Friction Factor Enhancement Ratio (FFER) }}
$$

233 Where

234 (NNER) is Nusselt Number Enhancement Ratio which is evaluated by

$$
N N E R=\frac{(N u)_{R}}{(N u)_{S}}
$$

235 and

236 (FFER) is Friction Factor Enhancement Ratio which is evaluated by

$$
\text { FFER }=\left(\frac{f_{R}}{f_{S}}\right)^{1 / 3}
$$

237

238 Another parameter has been investigated and proposed by Lewis (1975) which is given as: 239

$$
\eta_{T H P P}=\frac{\left(S t_{R} / S t_{S}\right)}{\left(f_{R} / f_{S}\right)^{1 / 3}}
$$


241 The Eq. 14 (a) given by Lewis (1975) for evaluating THPP can be stated as:

243

$$
\text { THPP }=\frac{\text { Stanton Number Enhancement Ratio (SNER) }}{\text { Friction Factor Enhancement Ratio (FFER) }}
$$

244 Where (SNER) is Stanton Number Enhancement Ratio which is evaluated by

$$
S N E R=\frac{(S t)_{R}}{(S t)_{S}}
$$

245 While the (FFER) is evaluated by Eq. (13).

246

247 It is observed by authors that THPP is less sensitive towards the FFER. The deviation between the 248 terms $\left(f_{R} / f_{S}\right)$ and $\left(f_{R} / f_{S}\right)^{0.33}$ has been found $48 \%$ to $64 \%$ for the range of roughness and other 249 parameters with $(\mathrm{Re}) 2900$ - 14,000, which has been used for the present study.

250 Therefore, in order to evaluate in equal proportions of enhancement in heat transfer $(\mathrm{Nu})$ and friction 251 factor (f) a new parameter has been proposed and introduced which is more realistic named as 252 Thermo-hydraulic Improvement Parameter (THIP), and it can be evaluated as

$$
\left(\varepsilon_{\text {THIP }}\right)=\left[\frac{(N N I F)}{(F F I F)}\right]
$$

253 Where

254 (NNIF) is Nusselt Number Improvement Factor which is calculated by

$$
N N I F=\left[\frac{(N u)_{R}-(N u)_{S}}{(N u)_{S}} \times 100\right]
$$

255 and

256 (FFIF) is Friction Factor Improvement Factor which is calculated by

$$
F F I F=\left[\frac{\left(f_{R}\right)-\left(f_{S}\right)}{\left(f_{S}\right)} \times 100\right]
$$

257 Where 
$\left(\varepsilon_{\text {THIP }}\right)>1$ means NNIF values is higher and dominated the FFIF, which is desirable

\section{$259 \quad$ Validity test}

260

The experimental $\mathrm{Nu}_{\text {exp }}$ and $\mathrm{f}_{\exp }$ for smooth plate $\mathrm{SAH}$ has been calculated and compared with values obtained from the Dittus-Boelter equation for $(\mathrm{Nu})$ and modified Blasius equation for

263

$$
N u_{s}=0.024 \operatorname{Re}^{0.8} \operatorname{Pr}^{0.4}
$$

264

$$
f_{s}=0.085 \mathrm{Re}^{-0.25}
$$

265

266

267

268 269

The comparison plots are shown in Figs 4 and 5. The comparison results shows that the Nusselt number values have a mean deviation of $\pm 2.3 \%$. Likewise, experimental values of friction factor $\left(f_{\exp }\right)$ with data obtained by modified Blasius equation shows the average of deviation of $\quad \pm$ $2.5 \%$.

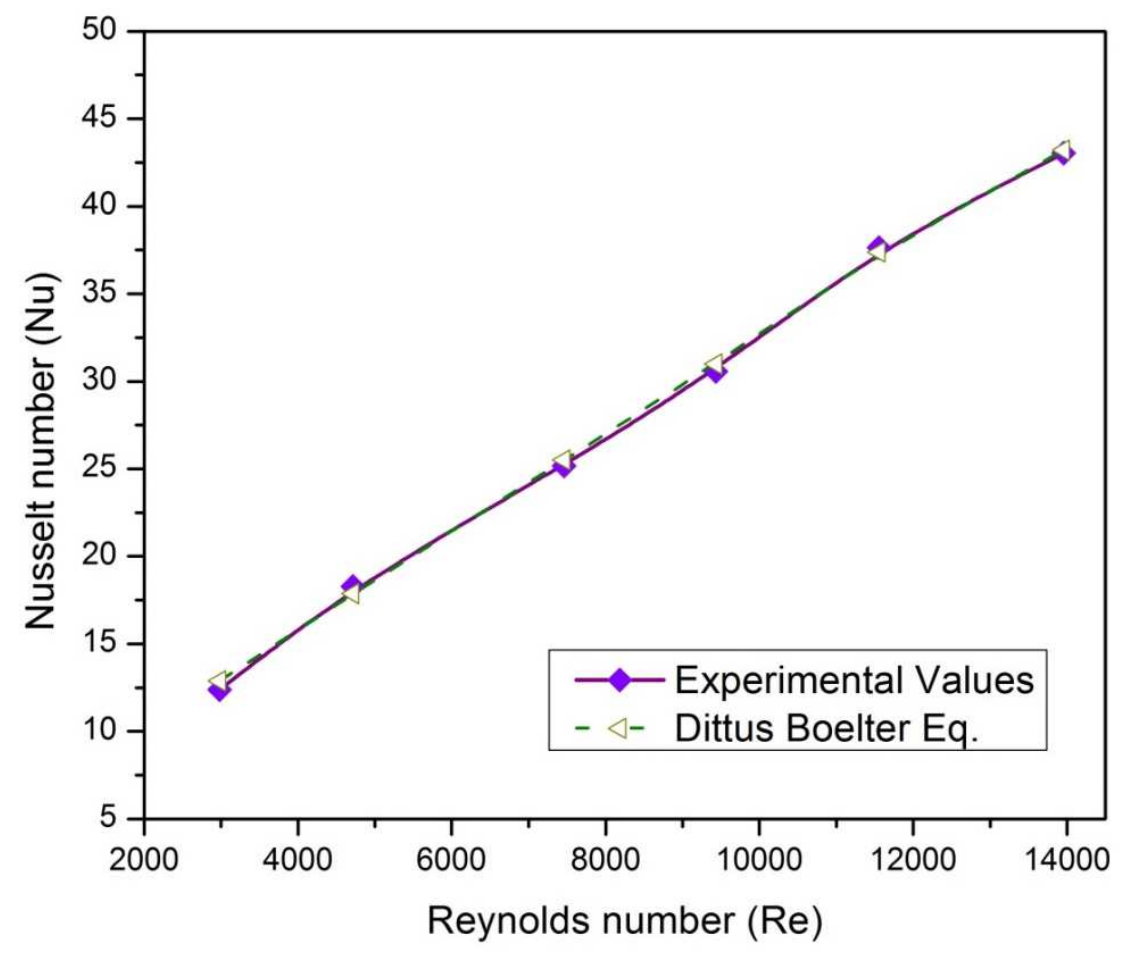

Fig. 4. Comparison of experimental and theoretical values of $\left(\mathrm{Nu}_{\mathrm{s}}\right)$ for smooth $\mathrm{SAH}$. 


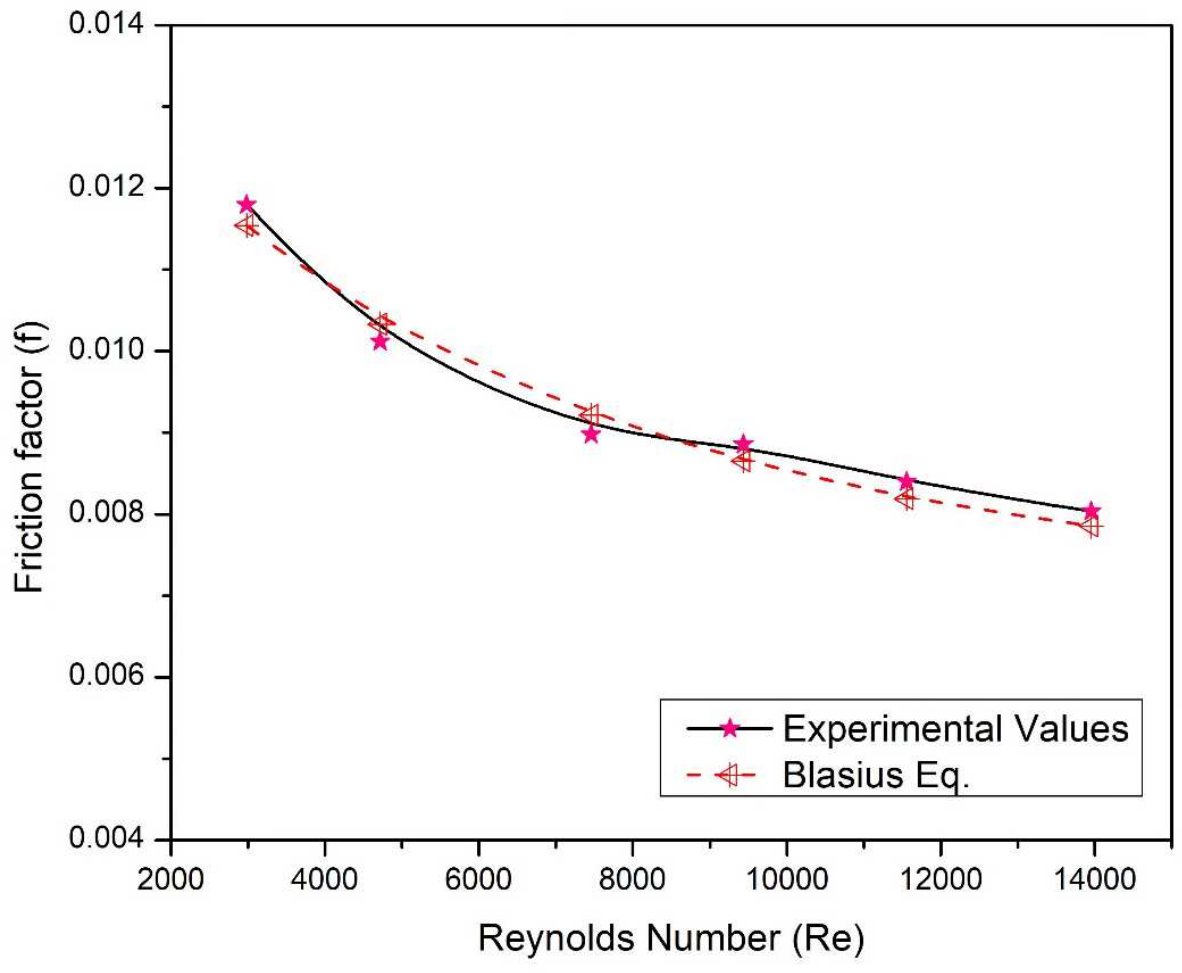

Fig. 5 Comparison of experimental values and theoretical values of (f) for smooth SAH.

An uncertainty or error analysis has been carried out as per the procedure described by Kline and Mc Clintok (1953). The uncertainties associated with various parameters have been calculated, and the values are ranges from 1.8 to $2.10 \%$ for Reynolds number, $1.42 \%$ to $4.78 \%$ for Nusselt number and $3.6 \%$ to $6.89 \%$ for friction factor. The evaluation of uncertainties for different parameters have been given in Appendix-B.

\section{Results and Discussion}

The Nusselt number and friction factor for smooth and arc-shaped roughened (Apex up streamflow) SAH have been evaluated, and their performances were compared based on THPP and THIP. The detailed results have also been presented in the following subsections.

\section{Influence of Relative Roughness Pitch (P/e)}

The influence of relative roughness parameter on the Nusselt number and friction factor have been presented in figures 6 to 9, for the Reynolds number which is ranging from 2900 to 14,000 
291 with fixed relative roughness height ratio of $(\mathrm{e} / \mathrm{D})=0.0454$, and relative angle of $\operatorname{arc}(\alpha)=60^{\circ}$. The

292 figures show that the Nusselt number has been increasing, and the friction factor has decreased with 293 an increase in Reynolds number for all the values of P/e and smooth plate SAHs. The presence of 294 artificial roughness makes a significant improvement in Nusselt number and friction factor 295 compared with the conventional system.

296 From Figs. 6 and 7, it is observed that the maximum value of Nusselt number and Nusselt 297 number enhancement ratio was attained at the relative roughness pitch (P/e) value of 8 . The 298 maximum value of NNER were found 2.83 for $(\mathrm{Re})=13955,(\mathrm{P} / \mathrm{e})=8, \alpha=60^{\circ}$ and $(\mathrm{e} / \mathrm{D})=0.0454$.

299 Further increasing in P/e value decreases the heat transfer rate. This happens due to that increase in 300 P/e values not reattach the primary flow with secondary flow, which reduces the number of 301 reattachment points and formulate the boundary layer that acts as a barrier to heat transfer. This 302 result agrees with the results reported by (Lanjewar et al. (2011); Singh et al. (2014); Hans et al. 303 (2010); Kumar et al. (2017); and Hans et al. (2010).

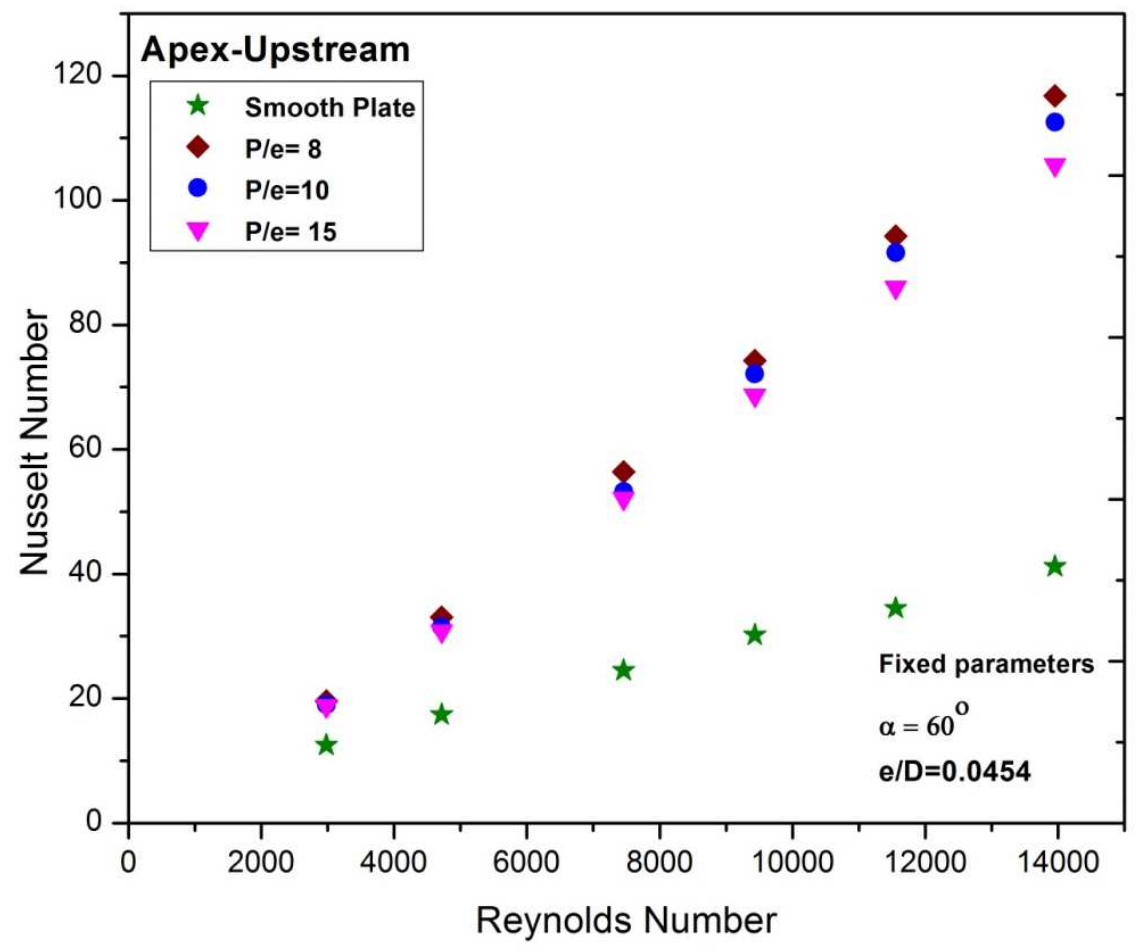

Fig. 6 Variation of Nusselt number with Reynolds number for different relative pitch (P/e). 


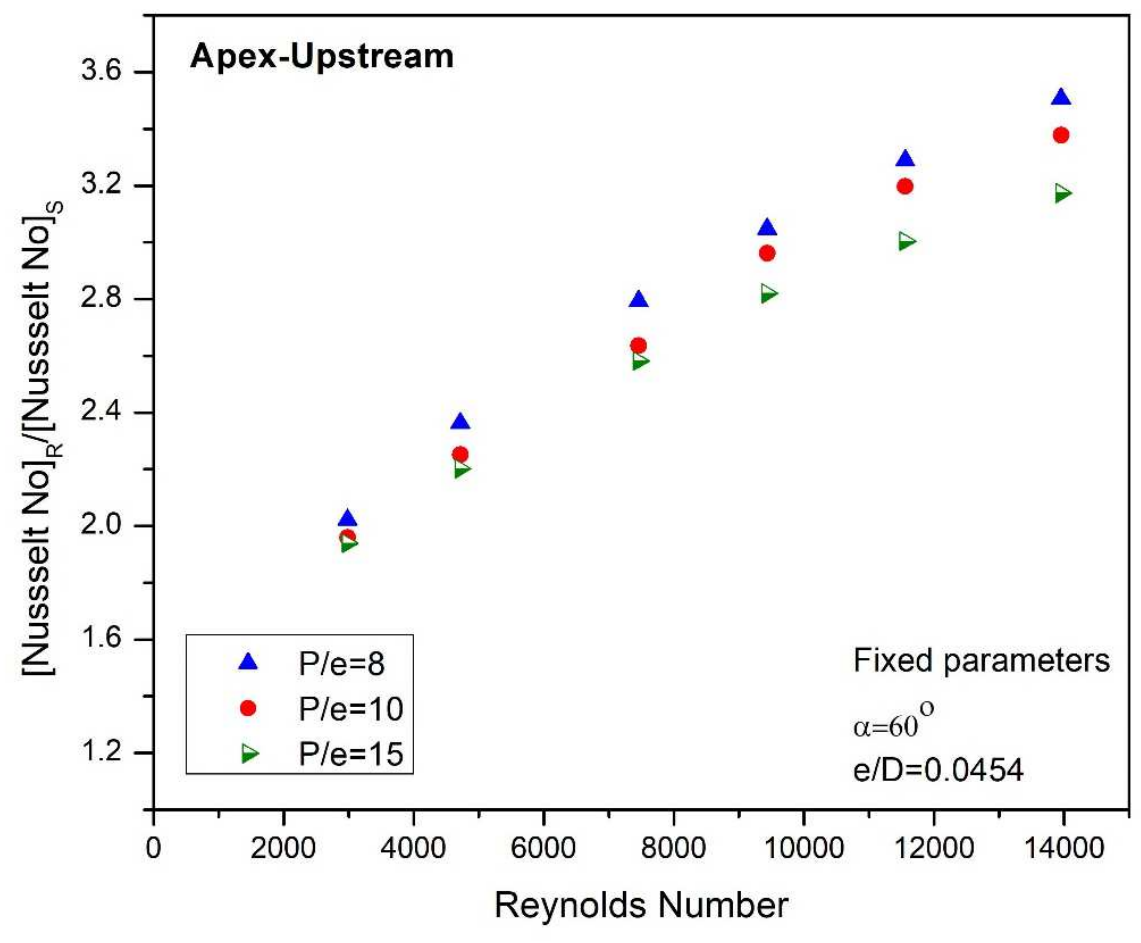

306

307

308

309

310

311

312

313

314

315

From the Figs. 8 and 9, it is observed that the maximum value of friction factor and friction enhancement ratio was attained at the relative roughness pitch $(\mathrm{P} / \mathrm{e})$ value of 8 . The maximum value of FFER was found 2.25 for $(\mathrm{Re})=13955,(\mathrm{P} / \mathrm{e})=8, \alpha=60^{\circ}$ and $(\mathrm{e} / \mathrm{D})=0.0454$.

13 The presence of rib roughness creates flow turbulence and offers more flow resistance hence friction 14 factor for roughened surface is more as compared to smooth SAH. 


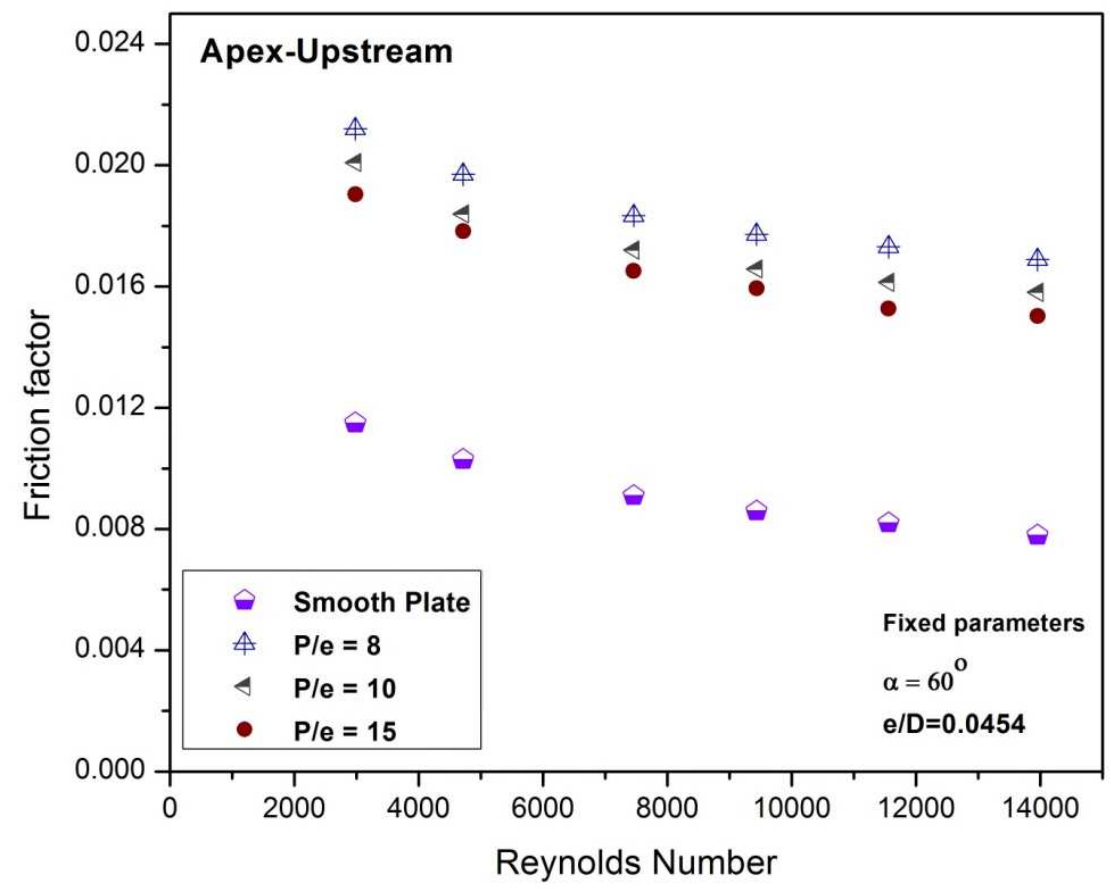

316

Fig. 8 Variation of Friction factor with Reynolds number for different relative pitch (P/e).

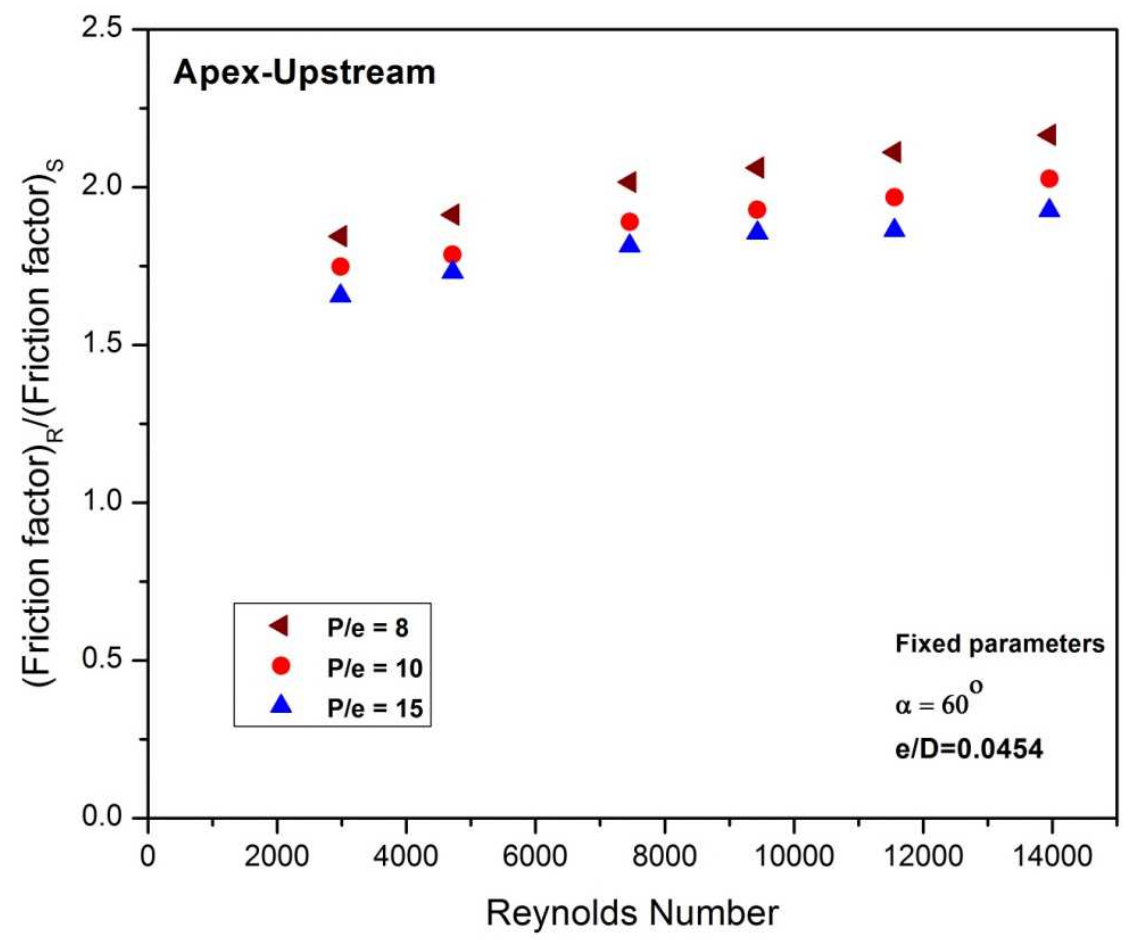

Fig. 9 Friction factor enhancement ratio (FFER) with Reynolds number for different relative pitch 320 (P/e). 
The influence of angle of attack ( $\boldsymbol{\alpha})$ on the Nusselt number and friction factor have been presented in Figs. 10 to 13, for the Reynolds number ranging from 2900 to 14,000 with fixed relative roughness height ratio of $(\mathrm{e} / \mathrm{D})=0.0454$, and relative roughness pitch $(\mathrm{P} / \mathrm{e})=8$.

The figures show that the Nusselt number has been increasing, and the friction factor has

327 been decreasing with an increase in Reynolds number and for all the values of $(\alpha)$ and smooth plate 328 SAHs.

From the Figs. 10 and 11, it is observed that the maximum value of Nusselt number and 330 Nusselt number enhancement ratio was attained at the angle of arc $(\alpha)$ value of $60^{\circ}$. The Nusselt number increases with a rise in the angle of arc from $45^{\circ}$ to $60^{\circ}$. Further increment in an angle of arc reduces heat transfer.

333 This happened due to fact that the angling of arc at this value in the form of artificial roughness 334 improves the Nusselt number and friction factor due to the formulation of more moving vortices as 335 compared to other values of $(\alpha)$.

336 When all the design parameters remain constant, the maximum value of NNER was found as 2.83.

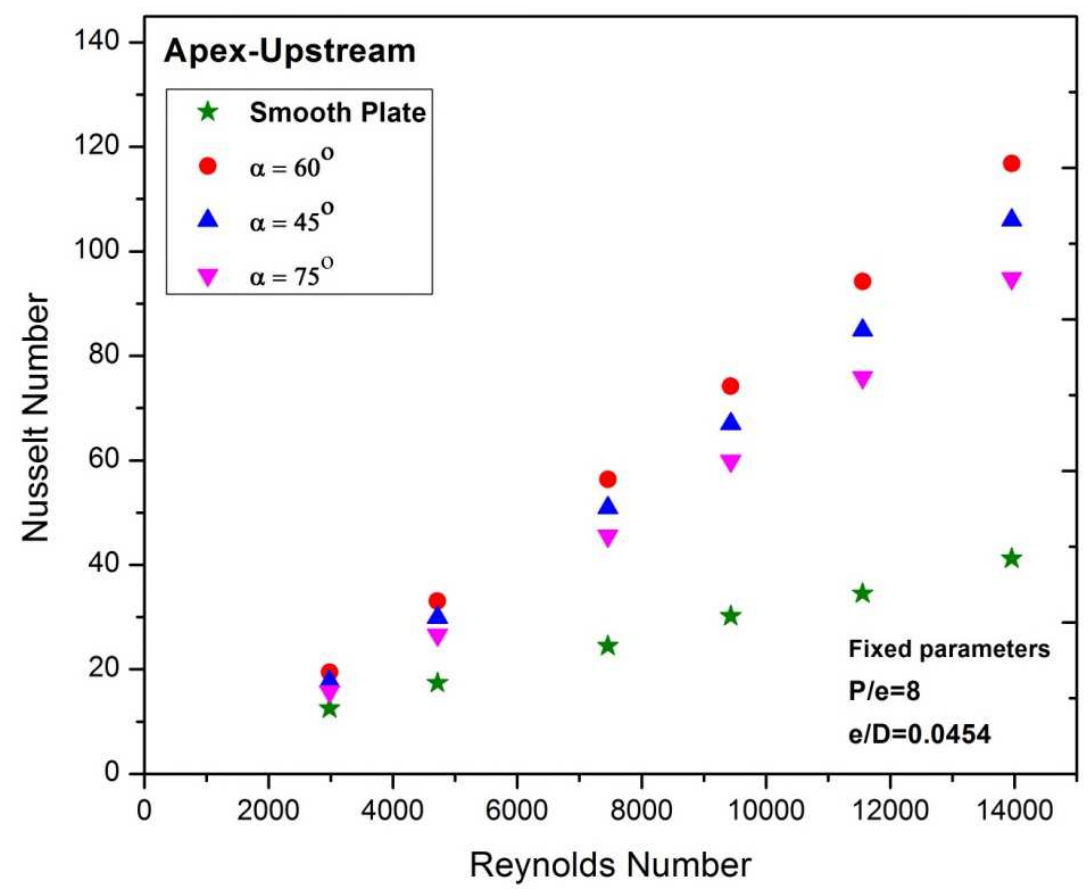

Fig.10 Nusselt number with Reynolds number for different angle of attack ( $\boldsymbol{\alpha})$. 


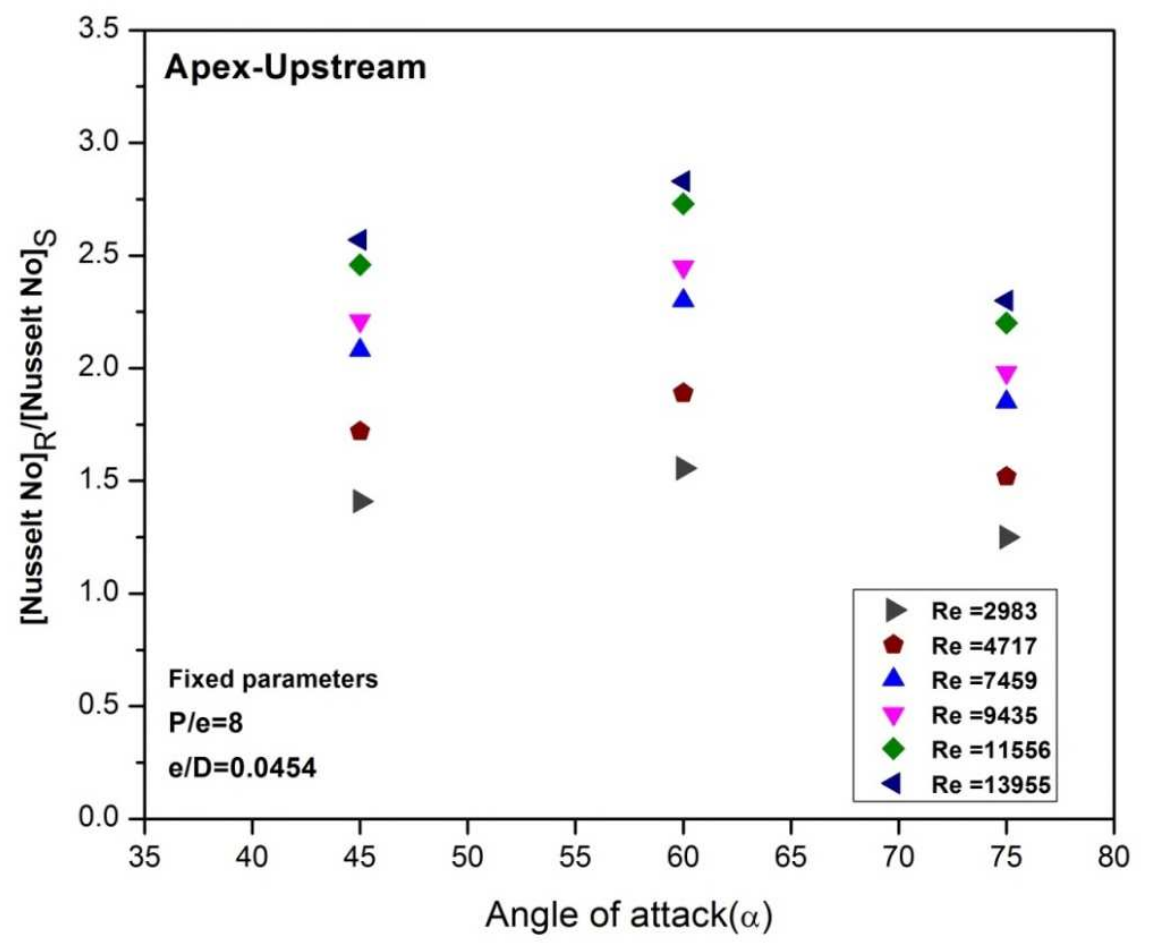

339

340

341

342

343

344

345

346

347

348 From Figs.12 and 13, are plotted to shows the effect of different ( $\boldsymbol{\alpha})$ on friction factor and friction 349 350 enhancement ratio was attained at the angle of $\operatorname{arc}(\boldsymbol{\alpha})=60^{\circ}$. 351

352

Fig. 11 Nusselt Number Enhancement Ratio (NNER) with (Re) for different values of $(\boldsymbol{\alpha})$.

By angling the roughness elements flow vortices effectively move from the leading edge of the rib to the trailing edge and formulate the high heat transfer zones. Further raise in an angle of $\operatorname{arc}(\boldsymbol{\alpha})$ from $60^{\circ}$ restrict the flow vortices and creates the dead zones.

This result agrees with the results reported by (Lanjewar et al. 2011; Singh et al. 2014; Hans et al. 2010; Kumar et al. 2017 and Hans et al. 2010).

349 enhancement ratio. It is observed that the maximum values of friction factor and friction 


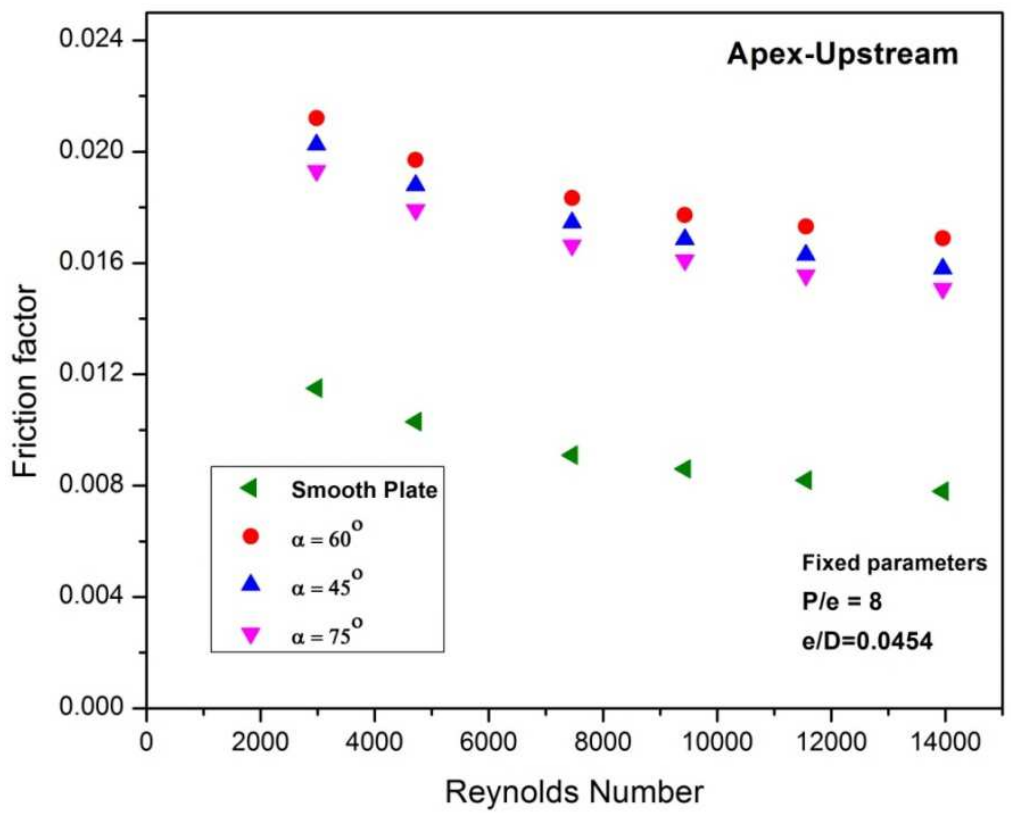

353

Fig. 12 Friction factor with Reynolds number for different angle of attack ( $\boldsymbol{\alpha})$.

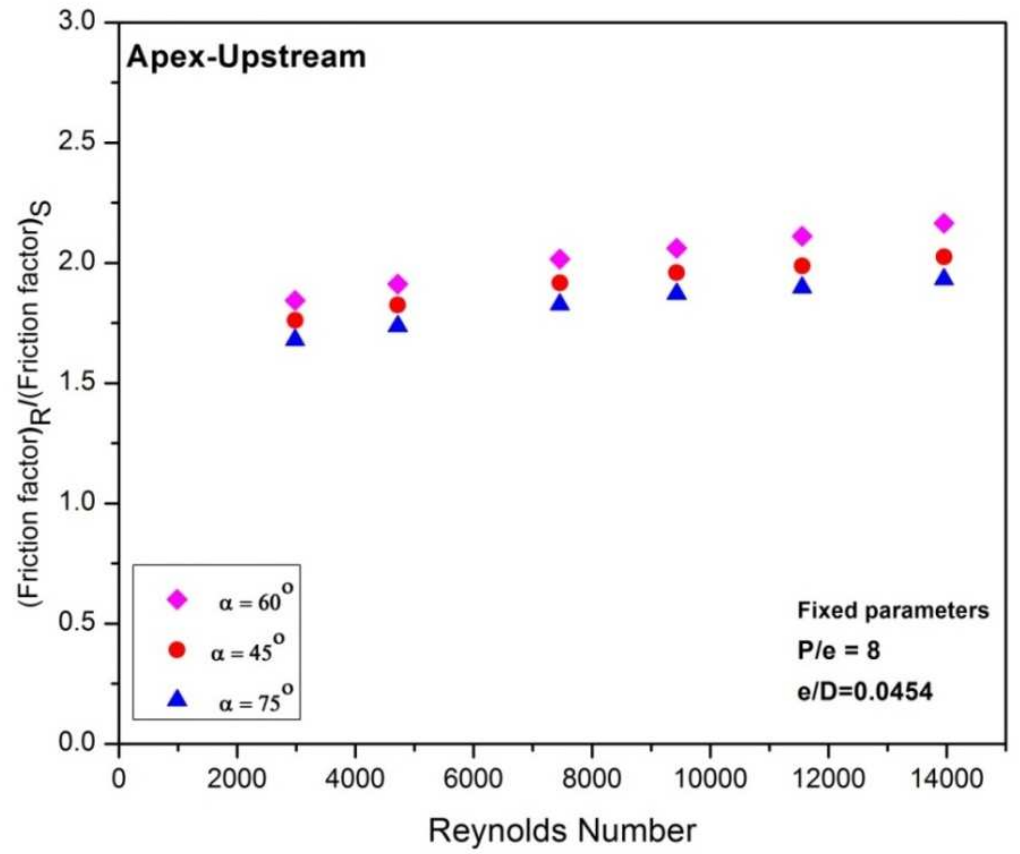

Fig. 13 Friction factor Enhancement Ratio (FFER) with Reynolds number for different angle of attack ( $\alpha)$.

The friction factor increases by increasing $(\alpha)$ values from $45^{\circ}$ to $60^{\circ}$ then it starts reduces while further raising in arc angle values. It happens because when the angle of arc is equal to $60^{\circ}$, 
361 the flow vortices offer more resistance over the leading edge of the rib and improve the friction

362 factor associated with pressure drop.

363 Thus, it can be seen from Fig.13 that the friction factor enhancement ratio ranges from 1.6 -2.1 in

364 the range of operating conditions.

\section{Thermo-Hydraulic Performance Parameter (THPP) based Comparison}

366 The thermo-hydraulic performance parameter (THPP) based comparison between present work and

367 other roughness configurations of SAHs (Momin et al. 2002; Lanjewar et al. 2011; Kumar et al.

368 2009; Gupta et al. 1997; Saini and Saini 2008) is shown in Fig. 14.

369 It can be seen from this Fig.14 that the arc-shape apex upstream roughened SAH curve follows the

370 similar pattern to the SAHs, having absorber plate with different roughness geometries, which

371 validates the precision of the results obtained from the present experimental work.

372 It can also be seen from Fig.14 that arc-shaped apex upstream roughened SAH had a maximum

373 value of THPP as compared to the THPP attained by other roughened SAHs for $\operatorname{Re}>7459$

374 (Approx.).

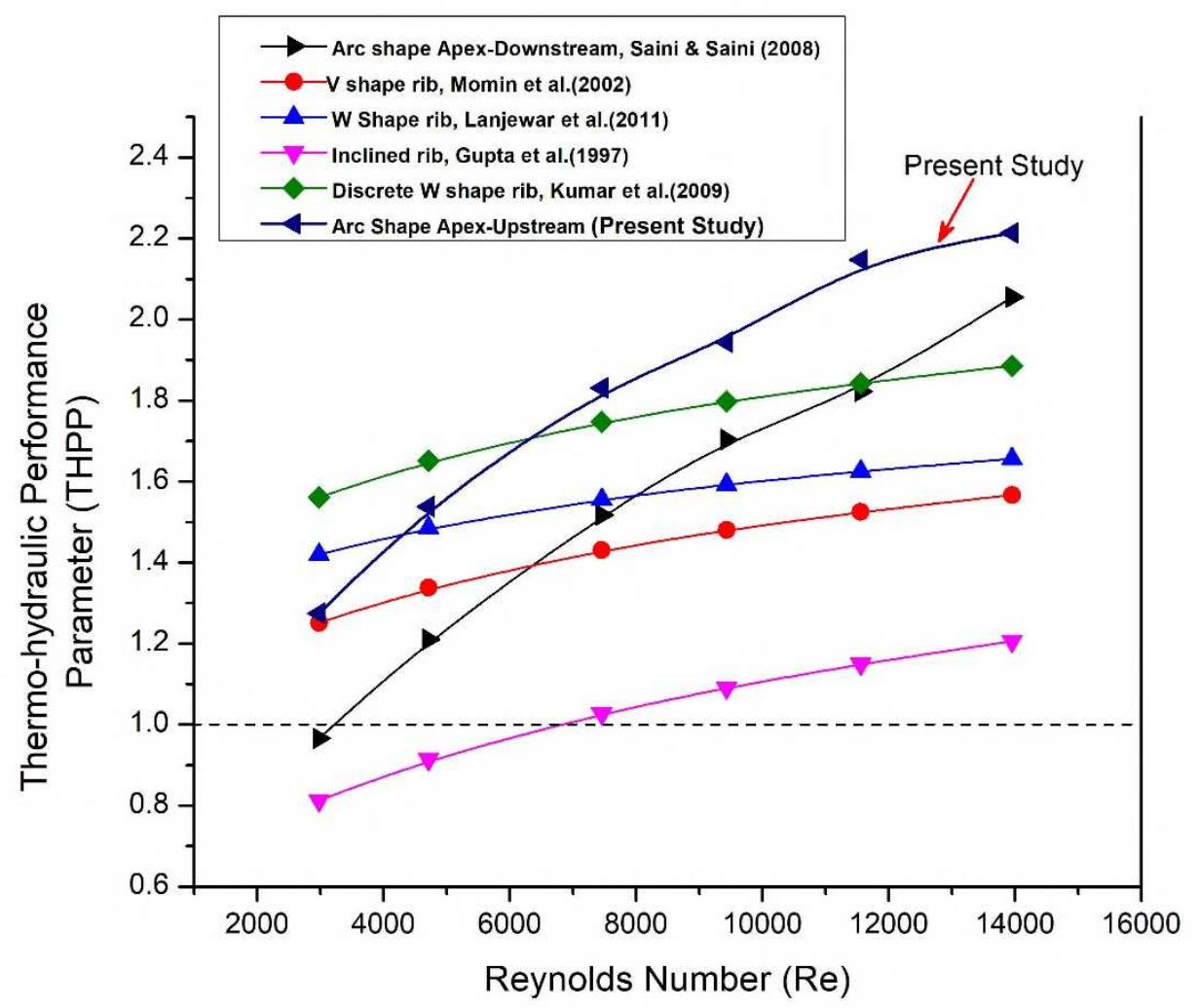


Fig.14 Thermo-hydraulic Improvement Parameter (THPP) comparison of present roughness geometry with others roughness geometries.

The THIP values with Reynolds numbers (Re) for present roughened SAH and other SAHs with different roughened absorber plate geometrical configuration under identical conditions have been evaluated and presented in Appendix-A, Tables- A1 to A6 for comparison.

It has been observed from Fig.15 that Thermo-hydraulic Improvement Parameter of present roughened SAH increases with $(\mathrm{Re})$. It also observed that the obtained THIP value for the present (arc shape) roughened SAH is having greater than one for Re > 5000 (Approx.)

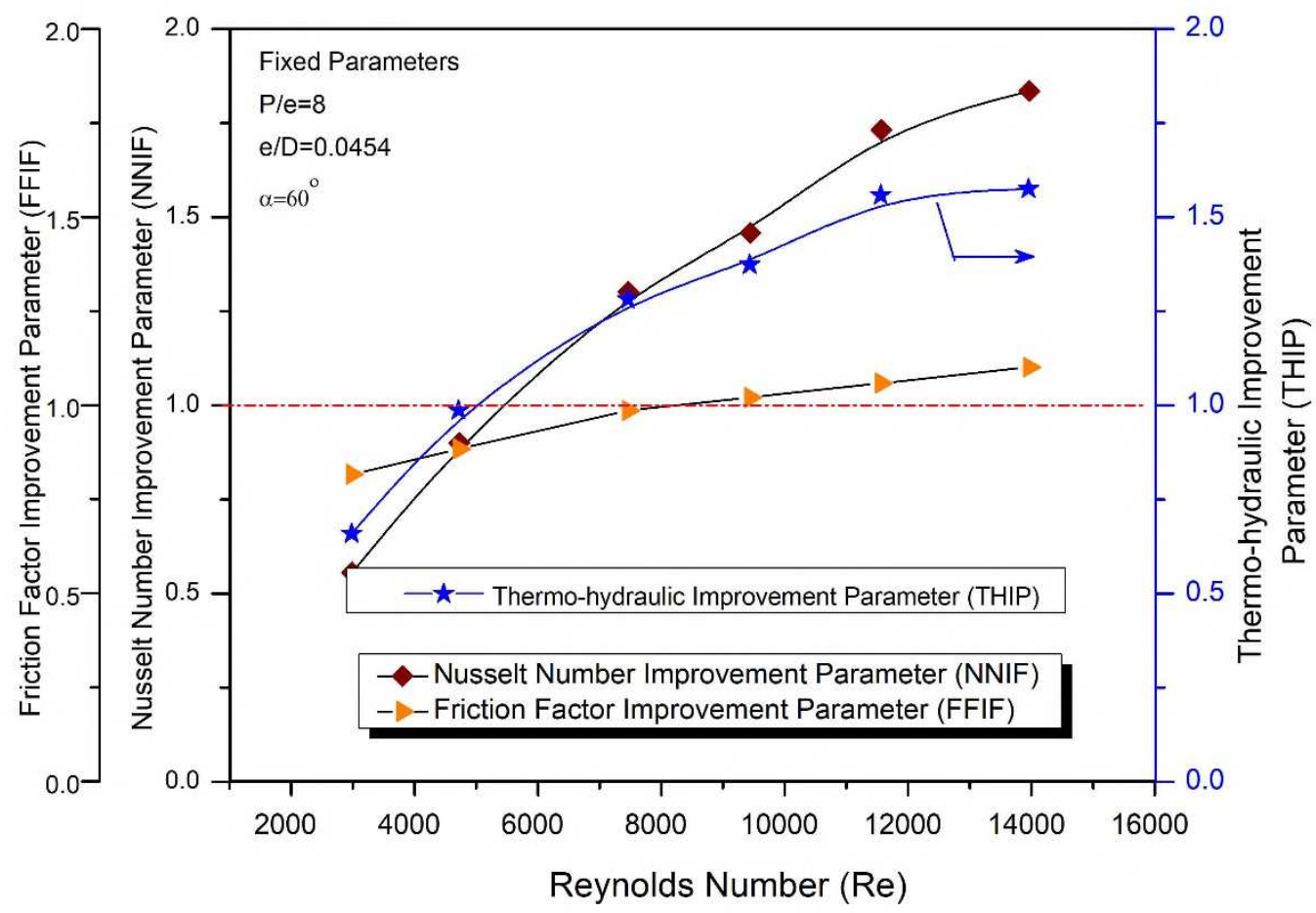

Fig.15 Comparison between Nusselt Improvement factor (NNIF), Friction factor Improvement factor (FFIF) and Thermo-hydraulic Improvement Parameter (THIP) for present roughness geometry SAH.

Fig. 15 also exemplifies the relationship between NNIF, FFIF, and THIP with Reynolds number for optimum values of roughness parameters. All these three parameters are increases with increases in (Re). The NNIF and FFIF increase from 0.555 to $1.834 \%$ and 0.816 to $1.108 \%$, respectively. The present Thermo-Hydraulic Improvement Parameter represents the actual performance of the SAH duct by considering the pressure loss enhancement ratio to the Nusselt 
number enhancement ratio. For present apex upstream SAH, THIP is found in the range of 65.82

$397 \%$ to $157.49 \%$.

398

399

400

401

$$
N u=N u(\operatorname{Re}, \mathrm{P} / \mathrm{e}, \alpha / 90)
$$

402

$$
f=f(\mathrm{Re}, \mathrm{P} / \mathrm{e}, \alpha / 90)
$$

403 Based on statistical regression analysis, correlations have been developed for $(\mathrm{Nu})$ and (fr) in 404 relation to roughness geometry and flow parameters by using the recorded experimental data.

\section{Nusselt number Correlations}

406

407

408

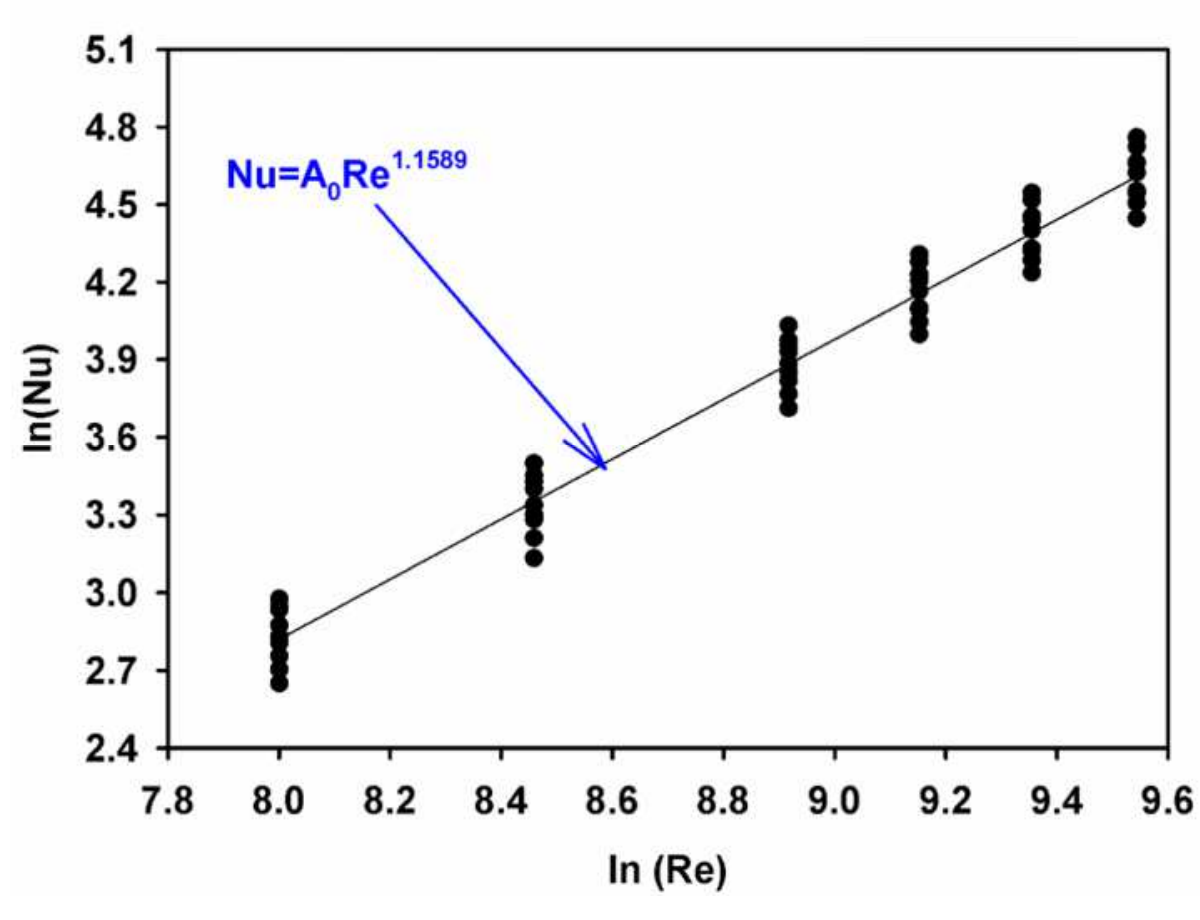

A functional relationship between Nusselt number and Reynolds number is accessed by plotting a graph for $(\mathrm{Nu})$ and $(\mathrm{Re})$. All the data points of the Nusselt number acquired from experimental results are plotted on a log-log scale against $(\mathrm{Re})$, as depicted in Fig.16. 
413 The curve fitting with a least-square fit for all data points, and it is identified that $(\mathrm{Nu})$ has a linear 414 association with (Re) (Kumar et al. 2020; Kumar V 2019). Further, it is revealed that the average 415 slope is 1.1589. Consequently, it can be written as

$$
N u=A_{0} \operatorname{Re}^{1.1589}
$$

416

417

418 419

420
424

425 The regression analysis shows that linear relationship between the data and the variation of the 426 function is obtained as

$$
\frac{N u}{\operatorname{Re}^{1.1589}}=B_{0}\left(\frac{P}{e}\right)^{-0.1467}
$$



roughness parameters such as relative angle of $\operatorname{arc}(\alpha / 90)$. Consequently, $\mathrm{Nu} / \mathrm{Re}^{1.1589}(\mathrm{P} / \mathrm{e})^{-0.1467}=\mathrm{B}_{0}$ was computed and plotted in log-log scale as a part of relative arc angle ( $\alpha / 90)$, as shown in Fig.18. 430 431

432

433

434

435 436

437 438 439

438

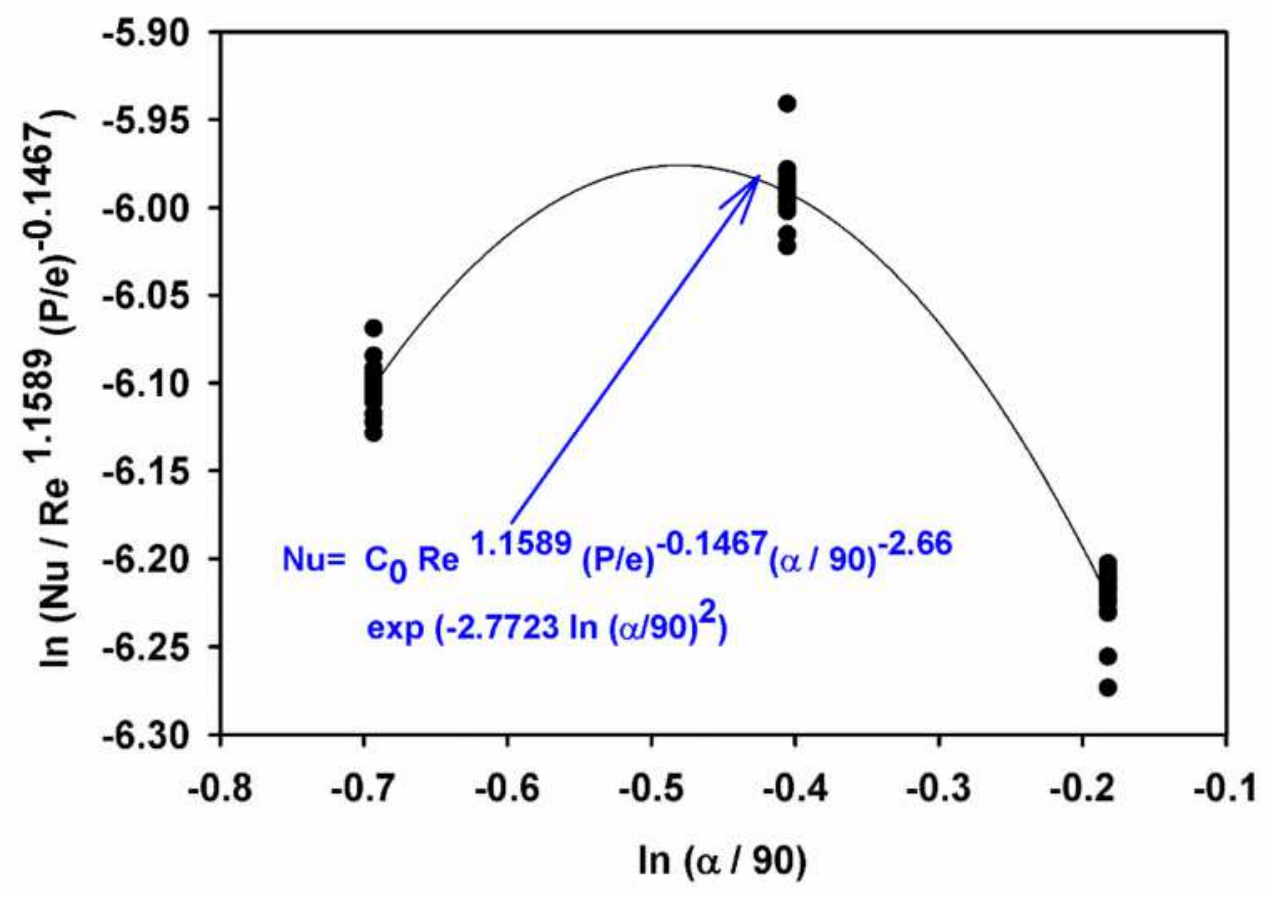

Fig.18 Plot of $\ln \left(\mathrm{Nu} / \mathrm{Re}^{1.1589}(\mathrm{P} / \mathrm{e})^{-0.1467}\right)=\ln \left(\mathrm{B}_{0}\right) \mathrm{VS}(\alpha / 90)$

By carried out the second-order regression analysis on the data points yields the relationship as follows.

$$
\frac{N u}{\operatorname{Re}^{1.1589}\left(\frac{P}{e}\right)^{-0.1467}}=C_{0}\left(\frac{\alpha}{90}\right)^{-2.66} \exp \left(-2.7723\left(\ln \left(\frac{\alpha}{90}\right)\right)^{2}\right)
$$

The regression analysis obtains the value of the coefficient $\mathrm{C}_{0}$. Further, by rearranging the Eqn.26, the relationship for Nusselt number is developed, and it is stated as

$$
N u=1.340 \times 10^{-3} \operatorname{Re}^{1.1589}\left(\frac{P}{e}\right)^{-0.1467}\left(\frac{\alpha}{90}\right)^{-2.66} \exp \left(-2.7723\left(\ln \left(\frac{\alpha}{90}\right)\right)^{2}\right)
$$


441

The identical techniques of statistical analysis have been utilized once again to derive the 442 friction factor correlations. Further, the relationship between the parameters is shown in Figs. 1944321.

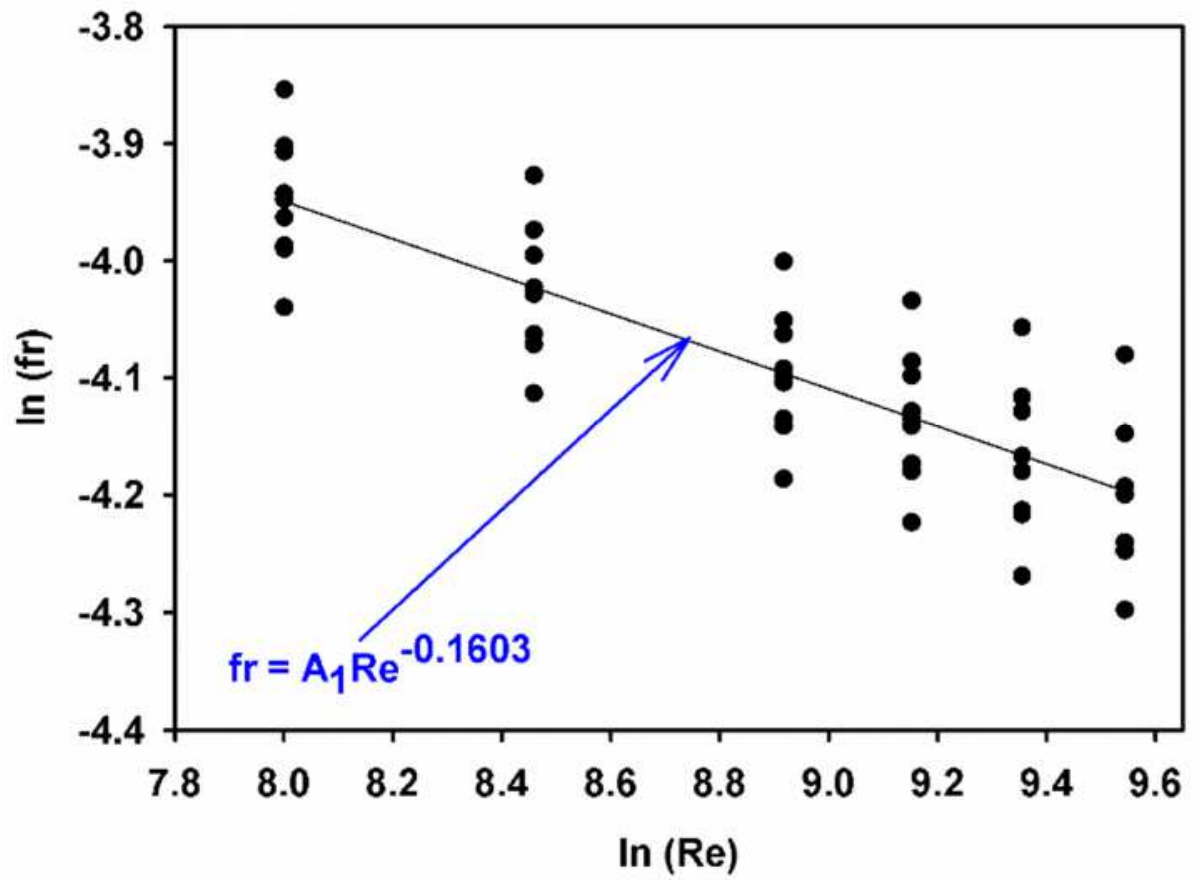

445

446

447

Fig.19 $\ln (\mathrm{fr}) \mathrm{VS} \ln (\mathrm{Re})$

448 


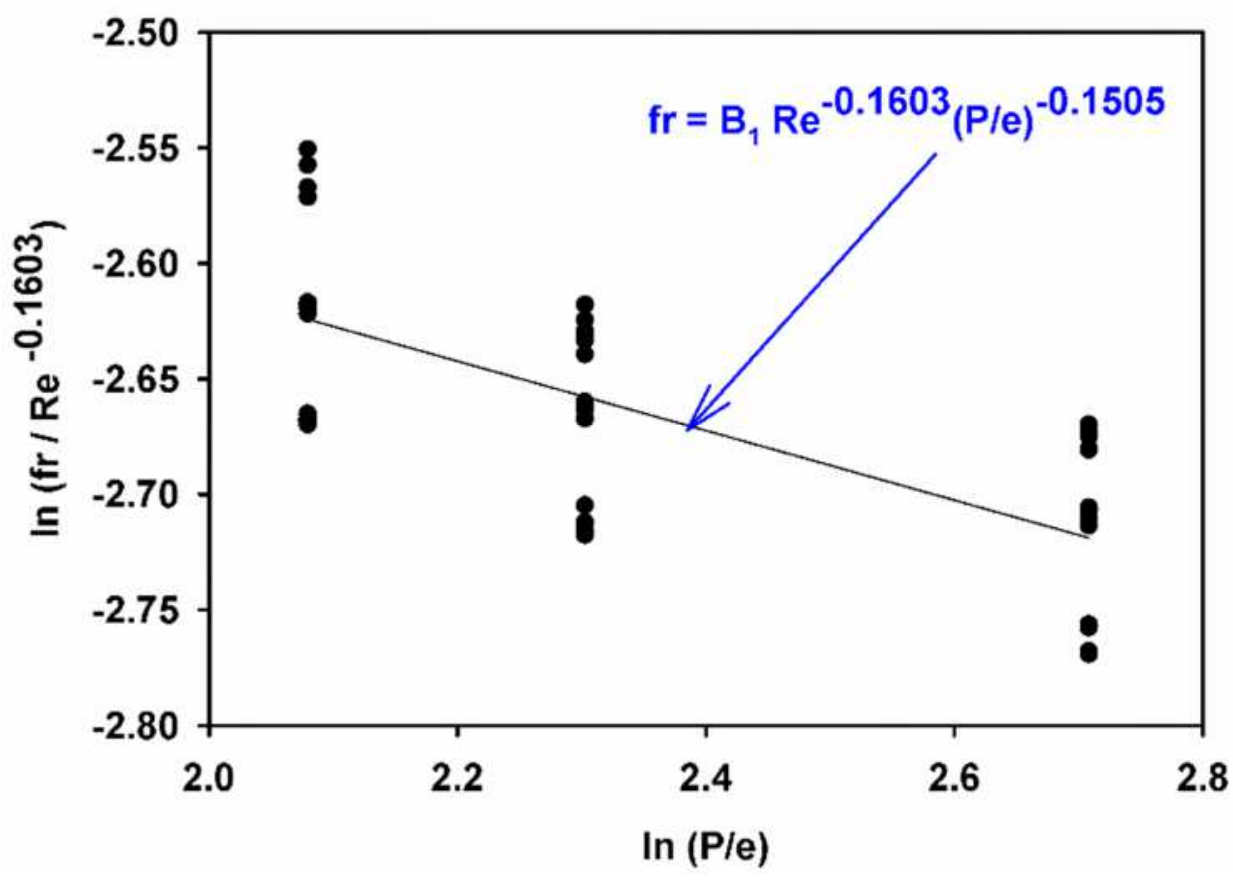

450

Fig. $20 \ln \left(\mathrm{Nu} / \mathrm{Re}^{-0.1603}\right)=\ln \left(\mathrm{A}_{1}\right) \mathrm{VS} \ln (\mathrm{P} / \mathrm{e})$

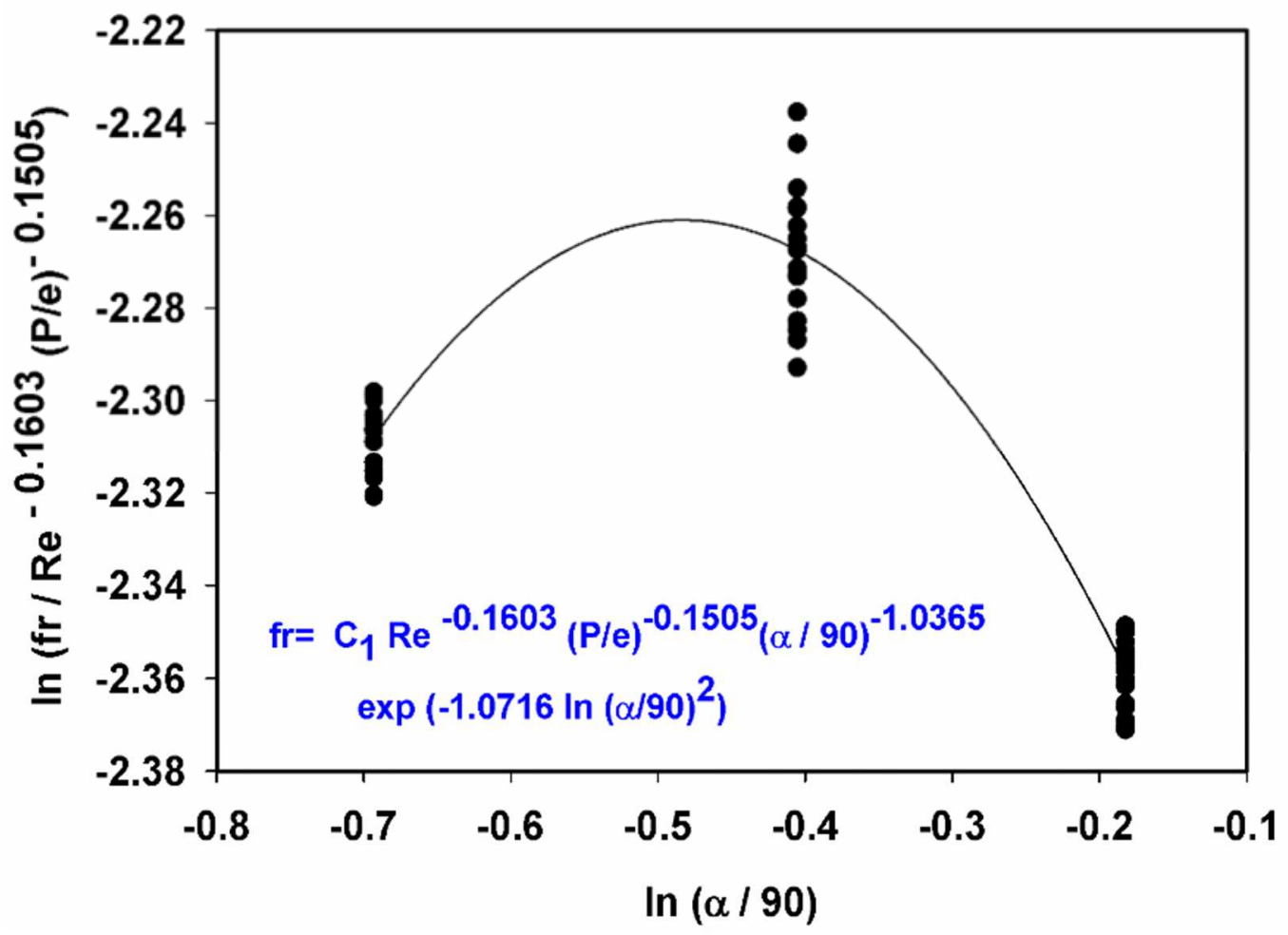

Fig. $21 \ln \left(\mathrm{Nu} / \mathrm{Re}^{-0.1603}(\mathrm{P} / \mathrm{e})^{-0.1505}\right)=\ln \left(\mathrm{B}_{1}\right) \mathrm{VS} \ln (\alpha / 90)$ 
455 The regression analysis results the final correlation as follows.

456

$$
f r=8.113 \times 10^{-2} \operatorname{Re}^{-0.1603}\left(\frac{P}{e}\right)^{-0.1505}\left(\frac{\alpha}{90}\right)^{-1.0365} \exp \left(-1.0716\left(\ln \left(\frac{\alpha}{90}\right)\right)^{2}\right)
$$

457

458 Comparison of experimental and predicted value of $(\mathrm{Nu})$ and $(\mathrm{fr})$

459

Fig. 21 and 22 show the deviation between experimental data $(\mathrm{Nu})$ and (fr) with predicted 460 values by developed co-relations via Eqn. 27 and 28, respectively.

461

462

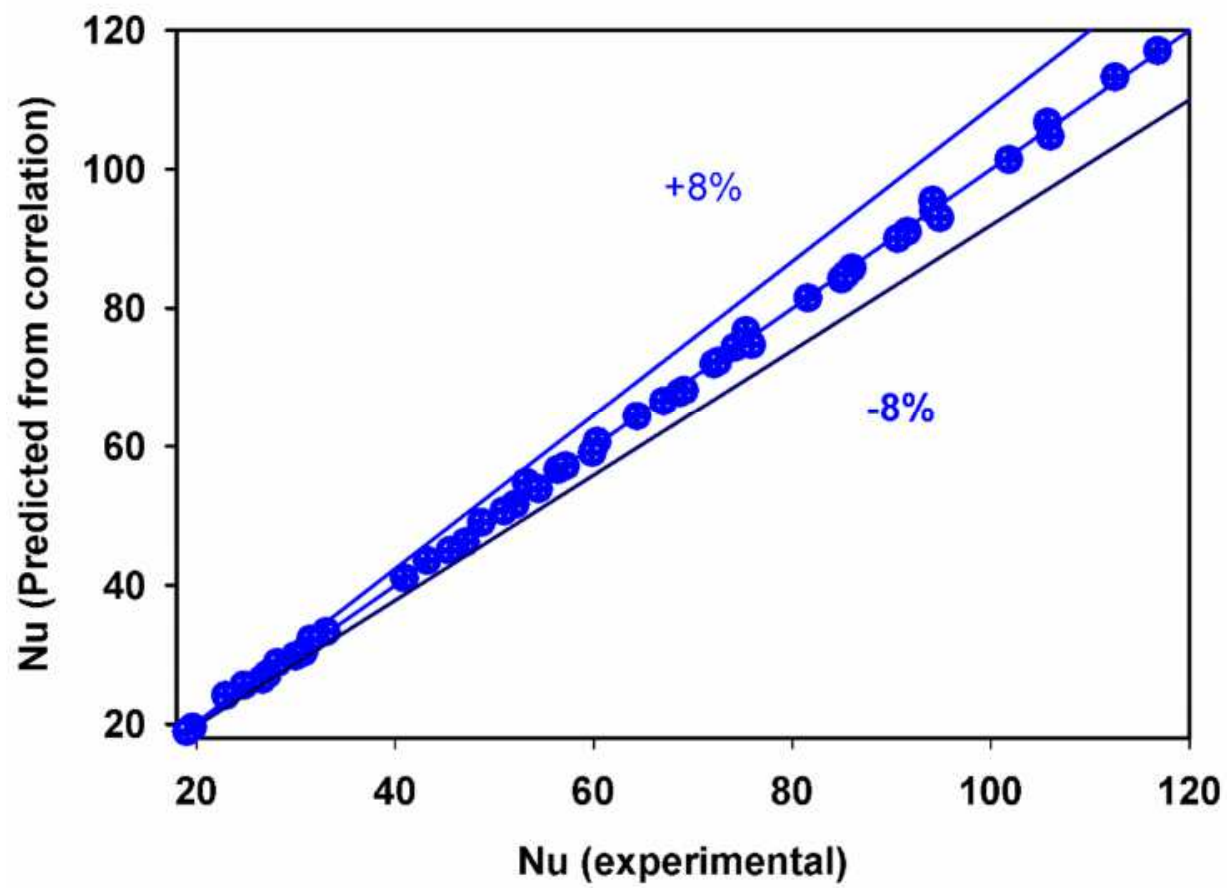

Fig.22. Comparison between Experimental and predicted Nusselt number 


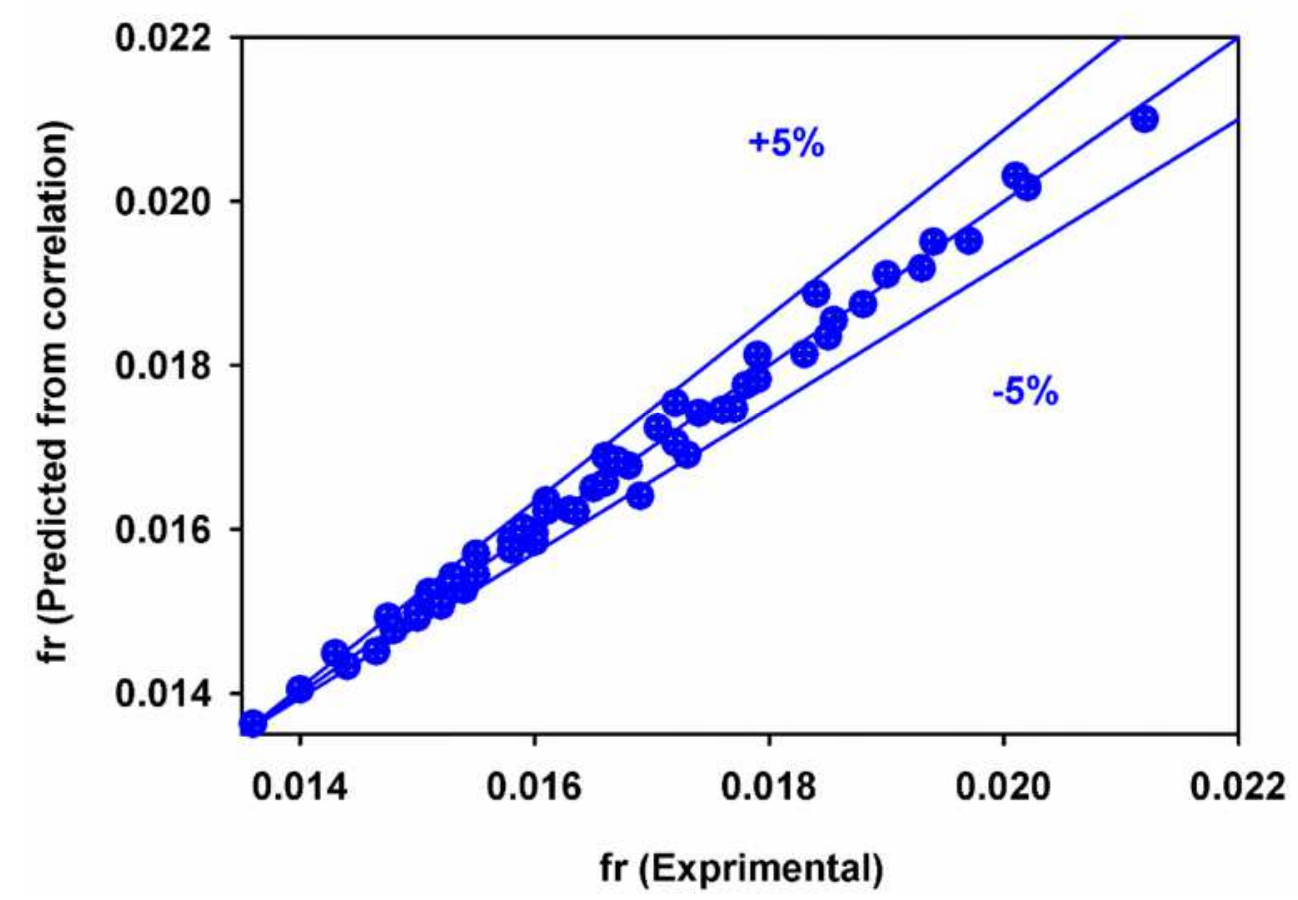

Fig.23. Comparison between Experimental and predicted friction factor

469 The predicted Nusselt number and friction factor deviation vary from the original values by a 470 maximum of $\pm 8 \%$ and $\pm 5 \%$, respectively. Further, the regression coefficient for the correlations are 4710.99 and 0.98 , respectively. From these statistical results, it is concluded that the correlations can 472 predict the values of $\mathrm{Nu}$ and fr with the required accuracy for the lower and upper bound values of 473 design and operating conditions. The suggested novel parameter can be utilized to compare the 474 various design of solar air heaters and optimize its design parameters. Due to higher values of 475 MTHIP, the arc-shaped roughness designs can be integrated with jet impingement and packed bed 476 solar air heaters to enhance its performance.

\section{Conclusions}

478 The following main conclusions were drawn based on the present experimental work and are given 479 as:

- For both the artificially roughened and flat plate SAHs, the heat transfer augmented with the increase in the values of Reynolds number at the same time friction factor for both ducts reduces with increase in $\mathrm{Re}$. 
- The maximum value of the thermal performance of the SAH was obtained at relative roughness pitch $(\mathrm{P} / \mathrm{e})=8$, angle of attack $(\alpha)=60^{\circ}$ and relative roughness height $(\mathrm{e} / \mathrm{D})=$ 0.0454 .

- Compared to the smooth absorber plate present, apex upstream roughened SAH has enhanced the NNER by 2.83 times and FFER by 1.83 times for the range of design and operating conditions as investigated.

- Nusselt Number Improvement factor (NNIF) and Friction Factor Improvement factor (FFIF) are 1.83 and 1.10 , respectively, for the investigated range of parameters. 


\section{Ethical Approval}

511

Not Appicable

512

513

514

515

516

517

518

519

520

521

522

523

524

525

526

527

528

529

530

531

532 
533 Consent to Participate

534

Not Appicable

535

536

537

538

539

540

541

542

543

544

545

546

547

548

549

550

551

552

553

554

555 
556 Consent to Publish

557

Not Appicable

558

559

560

561

562

563

564

565

566

567

568

569

570

571

572

573

574

575

576

577

578 
579 Authors Contributions

580 All authors contributed to the study conception and design of the manuscript. Material preparation, 581 data collection and analysis were performed by all authors: Mukesh Kumar Sahua,b, Manjeet 582 Kharub $^{\mathrm{c}}$, M. M. Matheswaran ${ }^{\mathrm{d}}$

583

584

585

586

587

588

589

590

591

592

593

594

595

596

597

598

599

600

601 
602 Funding

603 Authors have not received any funding support.

604

605

606

607

608

609

610

611

612

613

614

615

616

617

618

619

620

621

622

623

624 
625 Competing Interests

626

Not Appicable

627

628

629

630

631

632

633

634

635

636

637

638

639

640

641

642

643

644

645

646

647 
648 Availability of data and materials

649

Not Appicable

650

651

652

653

654

655

656

657

658

659

660

661

662

663

664

665

666 


\section{References}

668

669

670

671

672

673

674

675

676

677

678

679

680

681

682

683

684

685

686

687

688

689

690

691

692

693

694

695

696

697

698

Aharwal, K. R., Gandhi, B. K., and Saini, J. S., (2008) Experimental investigation on heat-transfer enhancement due to a gap in an inclined continuous rib arrangement in a rectangular duct of solar air heater, Renewable Energy., 33, pp. 585-96.

ASHRAE standard 93-97 (1977) Method of testing to determine the thermal performance of solar collector.

Bhatti M.S., Shah R.K. (1987) Turbulent flow convective heat transfer, in: Kakac S., Sash R.K., Aung W (Eds.), Handbook of single phase convective heat transfer, John Willey \& Sons, New York.

Cortes A and Piacentini R., (1990) Improvement of efficiency of a bare solar collector by means of turbulence promoters, Applied Energy, 36, pp. 253-261.

Duffie, J.A, and Beckman, W.A., (1974) Solar engineering of thermal processes, $1^{\text {st }}$ edition. New York: Wiley.

Garg H P, Prakash J. (2000), Solar energy fundamentals and applications. 1st ed. New Delhi: Tata McGraw-Hill.

Gill RS, Hans VS, Saini JS, Singh S. (2017) Investigation on performance enhancement due to staggered piece in a broken arc rib roughened solar air heater duct. Renew Energy,104, pp. 148-62.

Ghritlahre H. K., P. K. Sahu, Subhash Chand. (2020) Thermal performance and heat transfer analysis of arc shaped roughened solar air heater - An experimental study, Solar Energy, 199, pp. 173-182.

Gupta, D., Solanki, S. C., and Saini, J. S., (1997) Thermohydraulic performance of solar air heaters with roughened absorber plates, Solar Energy., 61, pp. 33-42.

Hans, V.S, Saini R.P and Saini J.S. (2010) Heat transfer and friction factor correlations for a solar air heater duct roughened artificially with multiple V-ribs. Solar Energy, 84, pp. 898-911.

Hans, V.S, Saini R.P and Saini J.S. (2010) Heat transfer and friction factor correlations for a solar air heater duct roughened artificially with multiple V-ribs. Solar Energy, 84, pp. 898-911.

Kabeel A.E., Mofreh H. Hamed, Z.M. Omara, A.W. Kandeal (2017), Solar air heaters Design configurations, improvement methods and applications - A detailed review, Renewable and Sustainable Energy Reviews, pp. 1189-1206. 
699

700

701

702

703

704

705

706

707

708

709

710

711

712

713

714

715

716

717

718

719

720

721

722

723

724

725

726

727

728

729

730

731

732

733

734

735

Kumar Rajneesh, Varun Goel, Mukesh Kumar (2020). Effect of providing gap in multiple-arc ribroughened solar air heater - Part 1. Journal of Mechanical Science and Technology, 34, pp. 2619-2625.

Kumar R, V Goel, S Bhattacharyya, VV Tyagi, AM Abusorrah. (2021) Experimental investigation for heat and flow characteristics of solar air heater having symmetrical gaps in multiple-arc rib pattern as roughness elements., Experimental Heat Transfer, ,pp. 1-18.

Kumar Rajneesh, Varun Goel, Paramvir Singh, Abhishek Saxena, Abhishek Singh Kashyap, Amit Rai. (2019), Performance evaluation and optimization of solar assisted air heater with discrete multiple arc shaped ribs. Journal of Energy Storage, Vol.26, https://doi.org/10.1016/j.est.2019.100978.Sukhatme S.P, Nayak J.P. (2011), Solar energy. 3rd ed. New Delhi: Tata McGraw Hill.

Kumar S., Kumar, R. Goel, V. Bhattacharyya, S. Issakhov. (2021) Exergetic performance estimation for roughened triangular duct used in solar air heaters., A. Journal of Thermal Analysis and Calorimetry.

Kumar Rajneesh, Abhishek Singh Kashyap, Paramvir Singh, Varun Goel, Khushmeet Kumar, (2020) Innovatively Arranged Curved-Ribbed Solar-Assisted Air Heater: Performance and Correlation Development for Heat and Flow Characteristics, J. Sol. Energy Eng., 142 (3).

Kumar Arvind, J.L. Bhagoria, R.M. Sarviya, (2009) Heat transfer and friction correlations for artificially roughened solar air heater duct with discrete W-shaped ribs, Energy Conversion and Management 50, pp. 2106-2117.

Kumar K, Prajapati D, Samir S. (2017) Heat transfer and friction factor correlations development for solar air heater duct artificially roughened with 'S' shape ribs. Exp Therm. Fluid Sci., 82, pp. 249-61. http://dx.doi.org/10.1016/j.expthermflusci. 2016.11.012.

Kumar V, (2019) Nusselt number and friction factor correlations of three sides concave dimple roughened solar air heater, Renewable Energy, Vol. 135, PP- 355-377.

Kline S.J., McClintock F.A. (1953) Describing uncertainties in single sample experiments, Mechanical Engineering, Vol. 75, pp. 3-8.

Lewis M. J., (1975) Optimizing the thermohydraulic performance of rough surfaces, International Journal of Heat and Mass Transfer, 18, pp. 1243-1248.

Lanjewar A, J.L. Bhagoria, R.M. Sarviya, (2011) Heat transfer and friction in solar air heater duct with W-shaped rib roughness on absorber plate, Energy ,36, pp. 4531-4541. 
Lanjewar, A., Bhagoria, J. L., and Sarviya, R. M., (2011) Experimental study of augmented heat transfer and friction in solar air heater with different orientations of W-Rib roughness, Exp. Thermal Fluid Sci., 35, pp. 986-95.

Momin, AME., Saini, J. S., and Solanki, S. C., (2002) Heat transfer and friction in solar air heater duct with v-shaped rib roughness on absorber plate, Int. J. Heat Mass Transfer., 45, pp. 338396.

Pandey NK, Bajpai VK, Varun., (2016) Experimental investigation of heat transfer augmentation using multiple arcs with gap on absorber plate of solar air heater. Sol Energy, 134, pp. 314-26.

Rohsenow W.M., Hartnett JP, (1998) Cho YI (Eds.), Handbook of Heat Transfer, McGraw Hill, New York.

Sahu Mukesh Kumar , Manoj Sharma, M. M. Matheswaran, Kinshuk Maitra, (2019), On the Use of Longitudinal Fins to Enhance the Performance in Rectangular Duct of Solar Air Heaters- A Review, J. Sol. Energy Engg, 141 (3), pp. 1 - 16.

Sahu Mukesh Kumar, Radha Krishna Prasad. (2016), A Review of the Thermal and Hydrodynamic Performance of Solar Air Heater with Roughened Absorber Plates. Journal of Enhanced Heat Transfer, Vol. 23 (1), pp. 47-89.

Singh A. P., Varun, Siddhartha. (2014) Effect of artificial roughness on heat transfer and friction characteristics having multiple arc shaped roughness element on the absorber plate, Solar Energy., 105, pp. 479-493.

Saini, S. K. and Saini, R. P., (2008) Development of correlations for Nusselt number and friction factor for solar air heater with roughened duct having arc-shaped wire as artificial roughness, Solar Energy., 82, pp. 1118-30.

Sahu M. K, R. K. Prasad. (2016) Investigation on Optimal thermohydraulic performance of a solar air heater having arc shaped wire rib roughness on absorber plate". International Journal of Thermodynamics, Vol. 19, pp. 214-224.

Sahu M. K., R. K. Prasad. (2016) Exergy based performance evaluation of solar air heater with arcshaped wire roughened absorber plate. Renewable Energy, Vol. 96, pp. 233-243.

Saini, R. P., and Singal, S. K., (2008) Investigation of thermal performance of solar air heater having roughness elements as a combination of inclined and transverse ribs on absorber plate, Renewable Energy., 133, pp. 1398-405. 
773 Singh A. P., Varun, Siddhartha. (2014) Effect of artificial roughness on heat transfer and friction characteristics having multiple arc shaped roughness element on the absorber plate, Solar Energy., 105, pp. 479-493.

Sahu M. K., R. K. Prasad. (2017) Thermohydraulic performance analysis of an arc shape wire roughened solar air heater. Renewable Energy, Vol. 108: pp. 598-614.

778

Sahu M. K, R. K. Prasad. (2017) Entropy generation and thermodynamic analysis of solar air heaters with artificial roughness on absorber plate, Archives of Thermodynamics, 38 (3), pp. 23 - 48.

Sahu M. K., M. M. Matheswaran, Pardeep Bishnoi. (2021) Experimental study of thermal performance and pressure drop on a solar air heater with different orientations of roughness, Journal of Thermal Analysis and Calorimetry, Vol.144, Pages 1417-1413.

Sahu Mukesh Kumar., Priyam, A., Mishra, S., Bishnoi, P. "A detailed review on research, technology, configurations and application of wire ribs as artificial roughness in rectangular solar air heater duct" Journal of Process Mechanical Engineering. Volume (235), Pages 1211 1234, 2021.

Webb, R. L. and Eckert, E. R. G., (1972) Application of rough surface to heat exchanger design, International Journal of Heat and Mass Transfer, 15, pp. 1647- 1658. 


\section{APPENDIX-A}

\section{VARIOUS PERFORMANCE PARAMETERS AND IMPROVEMENT FACTORS}

Table A 1: Various performance parameters and Improvement Factors for Arc Shape rib SAH, Saini and Saini (2008)

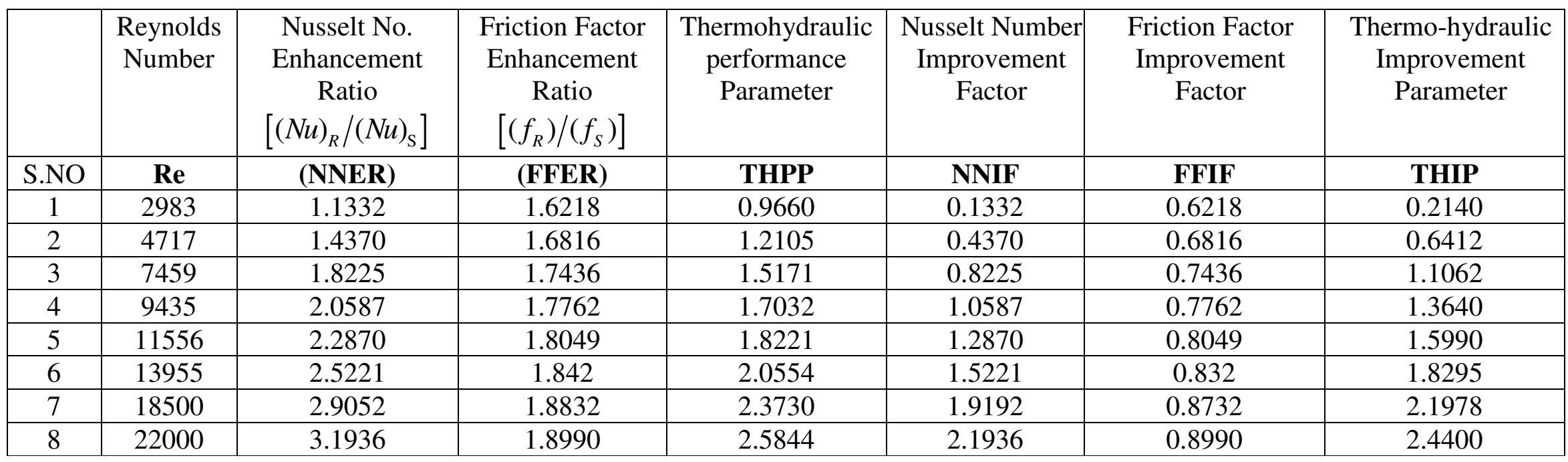

Table A 2: Various performance parameters and Improvement Factors for V-Shape rib SAH, Momin et al. (2002)

\begin{tabular}{|c|c|c|c|c|c|c|c|}
\hline & $\begin{array}{c}\text { Reynolds } \\
\text { Number }\end{array}$ & $\begin{array}{c}\text { Nusselt } \\
\text { No.Enhancement } \\
\text { Ratio } \\
{\left[(\mathrm{Nu})_{R} /(\mathrm{Nu})_{\mathrm{S}}\right]}\end{array}$ & $\begin{array}{c}\text { Friction } \\
\text { Factor } \\
\text { Enhancement } \\
\text { Ratio } \\
{\left[\left(f_{R}\right) /\left(f_{S}\right)\right]}\end{array}$ & $\begin{array}{c}\text { Thermohydraulic } \\
\text { performance } \\
\text { Parameter }\end{array}$ & $\begin{array}{c}\text { Nusselt Number } \\
\text { Improvement } \\
\text { Factor }\end{array}$ & $\begin{array}{c}\text { Friction Factor } \\
\text { Improvement } \\
\text { Factor }\end{array}$ & $\begin{array}{c}\text { Thermo-hydraulic } \\
\text { Improvement } \\
\text { Parameter }\end{array}$ \\
\hline S.NO & Re & $\mathbf{( N N E R )}$ & $\mathbf{( F F E R )}$ & THPP & NNIF & FFIF & THIP \\
\hline 1 & 2983 & 1.8309 & 3.1677 & 1.2515 & 0.8309 & 2.16 & 0.38834 \\
\hline 2 & 4717 & 1.9063 & 2.9236 & 1.3379 & 0.9063 & 1.9236 & 0.4712 \\
\hline
\end{tabular}




\begin{tabular}{|l|c|c|c|c|c|c|c|}
\hline 3 & 7459 & 1.9847 & 2.6983 & 1.4303 & 0.9847 & 1.6983 & 0.5798 \\
\hline 4 & 9435 & 2.0262 & 2.5896 & 1.4802 & 1.0262 & 1.5896 & 0.6456 \\
\hline 5 & 11556 & 2.0642 & 2.4993 & 1.5246 & 1.0627 & 1.4994 & 0.7088 \\
\hline 6 & 13955 & 2.097 & 2.4181 & 1.5671 & 1.0972 & 1.4181 & 0.7737 \\
\hline 7 & 18500 & 2.1499 & 2.3017 & 1.6328 & 1.1498 & 1.317 & 0.8834 \\
\hline 8 & 22000 & 2.1829 & 2.233 & 1.6746 & 1.1829 & 1.233 & 0.9594 \\
\hline
\end{tabular}

Table A 3: Various performance parameters and Improvement Factors for W-Shape rib SAH, Lanjewar et al.(2011).

\begin{tabular}{|c|c|c|c|c|c|c|c|}
\hline & $\begin{array}{c}\text { Reynolds } \\
\text { Number }\end{array}$ & $\begin{array}{c}\text { Nusselt No. } \\
\text { Enhancement } \\
\text { Ratio } \\
{\left[(\mathrm{Nu})_{R} /(\mathrm{Nu})_{\mathrm{S}}\right]}\end{array}$ & $\begin{array}{c}\text { Friction Factor } \\
\text { Enhancement } \\
\text { Ratio } \\
{\left[\left(f_{R}\right) /\left(f_{S}\right)\right]}\end{array}$ & $\begin{array}{c}\text { Thermohydraulic } \\
\text { performance } \\
\text { Parameter }\end{array}$ & $\begin{array}{c}\text { Nusselt Number } \\
\text { Improvement } \\
\text { Factor }\end{array}$ & $\begin{array}{c}\text { Friction Factor } \\
\text { Improvement } \\
\text { Factor }\end{array}$ & $\begin{array}{c}\text { Thermo-hydraulic } \\
\text { Improvement } \\
\text { Parameter }\end{array}$ \\
\hline S.NO & $\mathbf{R e}$ & $\mathbf{( N N E R )}$ & $\mathbf{( F F E R )}$ & $\mathbf{T H P P}$ & $\mathbf{N N I F}$ & FFIF & THIP \\
\hline 1 & 2983 & 1.8198 & 2.1207 & 1.42 & 0.8198 & 1.1207 & 0.7315 \\
\hline 2 & 4717 & 1.9121 & 2.1447 & 1.4864 & 0.9121 & 1.1447 & 0.7967 \\
\hline 3 & 7459 & 2.009 & 2.169 & 1.556 & 1.009 & 1.169 & 0.8631 \\
\hline 4 & 9435 & 2.0606 & 2.1816 & 1.5929 & 1.0606 & 1.1816 & 0.8976 \\
\hline 5 & 11556 & 2.1062 & 2.1925 & 1.6255 & 1.1062 & 1.1925 & 0.9276 \\
\hline 6 & 13955 & 2.1495 & 2.2027 & 1.656 & 1.1495 & 1.2027 & 0.92557 \\
\hline 7 & 18500 & 2.2159 & 2.2181 & 1.7036 & 1.2159 & 1.2181 & \\
\hline 8 & 22000 & 2.2577 & 2.2275 & 1.7334 & 1.2577 & 1.2275 & 0.9982 \\
\hline
\end{tabular}


Table A 4: Various performance parameters and Improvement Factors for Inclined Continuous rib SAH, Gupta et al. (1997).

\begin{tabular}{|c|c|c|c|c|c|c|c|}
\hline & $\begin{array}{c}\text { Reynolds } \\
\text { Number }\end{array}$ & $\begin{array}{c}\text { Nusselt No. } \\
\text { Enhancement } \\
\text { Ratio } \\
{\left[(\mathrm{Nu})_{R} /(\mathrm{Nu})_{\mathrm{S}}\right]}\end{array}$ & $\begin{array}{c}\text { Friction Factor } \\
\text { Enhancement } \\
\text { Ratio } \\
{\left[\left(f_{R}\right) /\left(f_{S}\right)\right]}\end{array}$ & $\begin{array}{c}\text { Thermohydraulic } \\
\text { performance } \\
\text { Parameter }\end{array}$ & $\begin{array}{c}\text { Nusselt Number } \\
\text { Improvement } \\
\text { Factor }\end{array}$ & $\begin{array}{c}\text { Friction Factor } \\
\text { Improvement } \\
\text { Factor }\end{array}$ & $\begin{array}{c}\text { Thermo-hydraulic } \\
\text { Improvement } \\
\text { Parameter }\end{array}$ \\
\hline S.NO & Re & $\mathbf{( N N E R )}$ & $\mathbf{( F F E R )}$ & THPP & NNIF & FFIF & THIP \\
\hline 1 & 2983 & 1.0137 & 1.9542 & 0.8126 & 0.0137 & 0.9542 & 0.0143 \\
\hline 2 & 4717 & 1.1546 & 2.0318 & 0.9138 & 0.1546 & 1.0318 & 0.1498 \\
\hline 3 & 7459 & 1.3151 & 2.1125 & 1.0274 & 0.3152 & 1.1125 & 0.2832 \\
\hline 4 & 9435 & 1.4058 & 2.1552 & 1.0912 & 0.4058 & 1.1552 & 0.3513 \\
\hline 5 & 11556 & 1.4892 & 2.1926 & 1.1494 & 0.4892 & 1.1926 & 0.4101 \\
\hline 6 & 13955 & 1.5711 & 2.2281 & 1.2061 & 0.5712 & 1.2281 & 0.465 \\
\hline 7 & 18500 & 1.7021 & 2.2821 & 1.2064 & 0.7021 & 1.2821 & \\
\hline 8 & 22000 & 1.7879 & 2.316 & 1.3552 & 0.7879 & 1.316 & 0.5476 \\
\hline
\end{tabular}

Table A 5: Various performance parameters and Improvement Factors for Discrete W-Shape rib SAH, Kumar et al.(2009).

\begin{tabular}{|c|c|c|c|c|c|c|c|}
\hline & $\begin{array}{c}\text { Reynolds } \\
\text { Number }\end{array}$ & $\begin{array}{c}\text { Nusselt No. } \\
\text { Enhancement } \\
\text { Ratio } \\
{\left[(\mathrm{Nu})_{R} /(\mathrm{Nu})_{\mathrm{S}}\right]}\end{array}$ & $\begin{array}{c}\text { Friction Factor } \\
\text { Enhancement } \\
\text { Ratio } \\
{\left[\left(f_{R}\right) /\left(f_{S}\right)\right]}\end{array}$ & $\begin{array}{c}\text { Thermohydraulic } \\
\text { performance } \\
\text { Parameter }\end{array}$ & $\begin{array}{c}\text { Nusselt Number } \\
\text { Improvement } \\
\text { Factor }\end{array}$ & $\begin{array}{c}\text { Friction Factor } \\
\text { Improvement } \\
\text { Factor }\end{array}$ & $\begin{array}{c}\text { Thermo-hydraulic } \\
\text { Improvement } \\
\text { Parameter }\end{array}$ \\
\hline S.NO & $\mathbf{R e}$ & $\mathbf{( N N E R )}$ & $\mathbf{( F F E R )}$ & $\mathbf{T H P P}$ & $\mathbf{N N I F}$ & FFIF & THIP \\
\hline 1 & 2983 & 2.3266 & 3.3492 & 1.5614 & 1.3266 & 2.3492 & 0.5647 \\
\hline 2 & 4717 & 2.4057 & 3.1267 & 1.6515 & 1.4057 & 2.1267 & 0.6610 \\
\hline 3 & 7459 & 2.4876 & 2.9190 & 1.7468 & 1.4876 & 1.9190 & 0.7752 \\
\hline 4 & 9435 & 2.5306 & 2.8179 & 1.7978 & 1.5306 & 1.8179 & 0.8419 \\
\hline 5 & 11556 & 2.5683 & 2.7335 & 1.843 & 1.5683 & 1.7335 & 0.9047 \\
\hline 6 & 13955 & 2.6040 & 2.6581 & 1.8862 & 1.6040 & 1.6572 & \\
\hline 7 & 18500 & 2.6581 & 2.5472 & 1.9524 & 1.6581 & 1.5472 & 0.9678 \\
\hline 8 & 22000 & 2.6919 & 2.4819 & 1.9944 & 1.6919 & 1.4819 & 1.0717 \\
\hline
\end{tabular}


Table A 6: Various performance parameters and Improvement Factors for Present Study

\begin{tabular}{|c|c|c|c|c|c|c|c|c|}
\hline & $\begin{array}{l}\text { Reynolds } \\
\text { Number }\end{array}$ & $\begin{array}{c}\text { Nusselt No. } \\
\text { Enhancement } \\
\text { Ratio } \\
{\left[(\mathrm{Nu})_{R} /(\mathrm{Nu})_{\mathrm{S}}\right]}\end{array}$ & $\begin{array}{c}\text { Friction } \\
\text { Factor } \\
\text { Enhanceme } \\
\text { nt Ratio } \\
{\left[\left(f_{R}\right) /\left(f_{S}\right)\right]}\end{array}$ & $\begin{array}{c}\text { Deviation } \\
\text { Between the } \\
\text { term } \\
{\left[\left(f_{R}\right) /\left(f_{S}\right)\right]} \\
\& \\
{\left[\left(f_{R}\right) /\left(f_{S}\right)\right]^{\wedge .33}}\end{array}$ & $\begin{array}{l}\text { Thermo- } \\
\text { hydraulic } \\
\text { performance } \\
\text { Parameter }\end{array}$ & $\begin{array}{c}\text { Nusselt Number } \\
\text { Improvement } \\
\text { Factor }\end{array}$ & $\begin{array}{c}\text { Friction } \\
\text { Factor } \\
\text { Improvement } \\
\text { Factor }\end{array}$ & $\begin{array}{c}\text { Thermo- } \\
\text { hydraulic } \\
\text { Improvement } \\
\text { Parameter }\end{array}$ \\
\hline S.NO & $\mathbf{R e}$ & (NNER) & (FFER) & $(\%)$ & THPP & NNIF & FFIF & THIP \\
\hline 1 & 2983 & 1.5555 & 1.8166 & 48.8849 & 1.2748 & 0.5555 & 0.8166 & 0.6582 \\
\hline 2 & 4717 & 1.8997 & 1.8841 & 52.5483 & 1.5381 & 0.8997 & 0.8841 & 0.9860 \\
\hline 3 & 7459 & 2.3015 & 1.9856 & 57.9828 & 1.8312 & 1.3015 & 0.9856 & 1.2816 \\
\hline 4 & 9435 & 2.4576 & 2.0205 & 59.8263 & 1.9440 & 1.4576 & 1.0205 & 1.3734 \\
\hline 5 & 11556 & 2.7310 & 2.0587 & 61.8340 & 2.1469 & 1.7310 & 1.0587 & 1.5582 \\
\hline 6 & 13955 & 2.83495 & 2.1008 & 64.0333 & 2.2135 & 1.8349 & 1.1008 & 1.5749 \\
\hline
\end{tabular}




\section{APPENDIX-B}

\section{UNCERTAINTY ANALYSIS}

A methodology for evaluation of the uncertainty in experimental results which has been suggested by Kline and McClintock (1953), is used in the present work. The procedure is as below:

If a parameter is calculated using certain measured quantities as,

$$
\mathrm{Y}=\mathrm{y}\left(\mathrm{x}_{1}, \mathrm{x}_{2}, \mathrm{x}_{3}, \ldots \ldots \ldots, \mathrm{x}_{\mathrm{n}}\right)
$$

Then uncertainty in the measurement of " $y$ " is given as follows:

$$
\frac{\delta y}{y}=\left[\left(\frac{\partial y}{\partial x_{1}} \delta x_{1}\right)^{2}+\left(\frac{\partial y}{\partial x_{2}} \delta x_{2}\right)^{2}+\left(\frac{\partial y}{\partial x_{3}} \delta x_{3}\right)^{2}+\ldots . .\left(\frac{\partial y}{\partial x_{n}} \delta x_{n}\right)^{2}\right]^{0.5}
$$

\section{(1). Area of absorber plate $\left(\mathrm{A}_{\mathrm{c}}\right)$ :}

$$
\begin{aligned}
& A_{c}=W \times L \\
& \frac{\delta A_{c}}{A_{c}}=\left[\left(\frac{\delta L}{L}\right)^{2}+\left(\frac{\delta W}{W}\right)^{2}\right]^{0.5}
\end{aligned}
$$

\section{(2). Cross sectional area of air flow $\operatorname{duct}(\mathrm{A})$}

$$
\begin{aligned}
& A=W \times H \\
& \frac{\delta A}{A}=\left[\left(\frac{\delta W}{W}\right)^{2}+\left(\frac{\delta H}{H}\right)^{2}\right]^{0.5}
\end{aligned}
$$

\section{(3). Perimeter of duct (P)}

$$
\begin{aligned}
& P=2(W+H) \\
& \frac{\delta P}{P}=\left[\left(2 . \frac{\delta W}{W}\right)^{2}+\left(2 \frac{\delta H}{H}\right)^{2}\right]^{0.5}
\end{aligned}
$$

\section{(4). Hydraulic diameter of duct (D)}

$$
D=\frac{2 \cdot \mathrm{W} H}{(W+H)}
$$


$\frac{\delta D}{D}=\left[\left(\frac{\delta A}{A}\right)^{2}+\left(\frac{\delta P}{P}\right)^{2}\right]^{0.5}$

(5). Area of orifice meter $\left(A_{0}\right)$

$$
\begin{aligned}
& A_{o}=\frac{\pi}{4} \times D_{2}^{2} \\
& \frac{\delta A_{o}}{A_{o}}=\left[\frac{2 \delta D_{2}}{D_{2}}\right]
\end{aligned}
$$

(6). Density (p)

$$
\begin{aligned}
& \rho=\frac{P_{a t m}}{R \cdot T_{f o}} \\
& \frac{\delta \rho}{\rho}=\left[\left(\frac{\delta P_{a t m}}{P_{a t m}}\right)^{2}+\left(\frac{\delta T_{o}}{T_{o}}\right)^{2}\right]^{0.5}
\end{aligned}
$$

(7). Mass flow rate (m)

$$
\begin{aligned}
& m=C_{d} \cdot \mathrm{A}_{\mathrm{o}} \sqrt{\frac{2 \rho\left(\Delta P_{o}\right)}{1-\beta_{R}^{4}}} \\
& \frac{\delta m}{m}=\left[\left(\frac{\delta C_{d}}{C_{d}}\right)^{2}+\left(\frac{\delta A_{o}}{A_{o}}\right)^{2}+\left(2 \frac{\delta \rho}{\rho}\right)^{2}+\left(\frac{\delta\left(\Delta P_{o}\right)}{\left(\Delta P_{o}\right)}\right)^{2}\left(\frac{2 \cdot \beta_{R}^{3} \cdot \delta \beta_{R}}{1-\beta_{R}^{2}}\right)\right]^{0.5}
\end{aligned}
$$

(8). Reynolds number (Re)

$$
\begin{aligned}
& \operatorname{Re}=\frac{\rho V D}{\mu} \\
& \frac{\delta \operatorname{Re}}{\operatorname{Re}}=\left[\left(\frac{\delta V}{V}\right)^{2}+\left(\frac{\delta \rho}{\rho}\right)^{2}+\left(\frac{\delta D}{D}\right)^{2}+\left(\frac{\delta \mu}{\mu}\right)^{2}\right]^{0.5}
\end{aligned}
$$

(9) Useful heat gain $(\mathrm{Qu})$

$$
\begin{aligned}
& Q u=n C_{p a} . \Delta T \\
& \frac{\delta Q u}{Q u}=\left[\left(\frac{\delta m}{m}\right)^{2}+\left(\frac{\delta C_{p a}}{C_{p a}}\right)^{2}+\left(\frac{\delta(\Delta T)}{\Delta T}\right)^{2}\right]^{0.5}
\end{aligned}
$$


(10). Heat transfer coefficient (h)

$\frac{\delta h}{h}=\left[\left(\frac{\delta Q u}{Q u}\right)^{2}+\left(\frac{\delta A_{c}}{A_{c}}\right)^{2}+\left(\frac{\delta\left(\mathrm{T}_{\mathrm{pm}}\right)}{\left(\mathrm{T}_{\mathrm{pm}}\right)}\right)^{2}\right]^{0.5}$

(11). Nusselt number ( $\mathrm{Nu}$ )

$\frac{\delta N u}{N u}=\left[\left(\frac{\delta h}{h}\right)^{2}+\left(\frac{\delta D}{D}\right)^{2}+\left(\frac{\delta\left(\mathrm{K}_{\mathrm{a}}\right)}{\left(\mathrm{K}_{\mathrm{a}}\right)}\right)^{2}\right]^{0.5}$

(12) Friction factor (f)

$\frac{\delta f}{f}=\left[\left(\frac{\delta\left(\mathrm{P}_{\mathrm{D}}\right)}{\left(\mathrm{P}_{\mathrm{D}}\right)}\right)^{2}+\left(\frac{\delta D}{D}\right)^{2}+\left(\frac{\delta\left(\mathrm{L}_{\mathrm{f}}\right)}{\left(\mathrm{L}_{\mathrm{f}}\right)}\right)^{2}+\left(\frac{\delta(\rho)}{(\rho)}\right)^{2}+\left(\frac{\delta(\mathrm{G})}{(\mathrm{G})}\right)^{2}\right]^{0.5}$ 